\title{
Short-Term Synaptic Plasticity Regulates the Level of Olivocochlear Inhibition to Auditory Hair Cells
}

\author{
Jimena Ballestero, ${ }^{1}$ Javier Zorrilla de San Martín, ${ }^{1}$ Juan Goutman, ${ }^{1}$ Ana Belén Elgoyhen,,${ }^{1,3}$ Paul A. Fuchs, ${ }^{4}$ \\ and Eleonora Katz ${ }^{1,2}$ \\ ${ }^{1}$ Instituto de Investigaciones en Ingeniería Genética y Biología Molecular, Consejo Nacional de Investigaciones Científicas y Técnicas, and ${ }^{2}$ Departamento \\ de Fisiología, Biología Molecular y Celular, Facultad de Ciencias Exactas y Naturales, Universidad de Buenos Aires, 1428 Buenos Aires, Argentina, ${ }^{3}$ Tercera \\ Cátedra de Farmacología, Facultad de Medicina, 1121 Buenos Aires, Argentina, and ${ }^{4}$ Department of Otolaringology, Head and Neck Surgery and Center for \\ Hearing and Balance, The Johns Hopkins University School of Medicine, Baltimore, Maryland 21205
}

In the mammalian inner ear, the gain control of auditory inputs is exerted by medial olivocochlear (MOC) neurons that innervate cochlear outer hair cells (OHCs). OHCs mechanically amplify the incoming sound waves by virtue of their electromotile properties while the MOC system reduces the gain of auditory inputs by inhibiting $\mathrm{OHC}$ function. How this process is orchestrated at the synaptic level remains unknown. In the present study, MOC firing was evoked by electrical stimulation in an isolated mouse cochlear preparation, while OHCs postsynaptic responses were monitored by whole-cell recordings. These recordings confirmed that electrically evoked IPSCs (eIPSCs) are mediated solely by $\alpha 9 \alpha 10 \mathrm{nAChRs}$ functionally coupled to calcium-activated SK2 channels. Synaptic release occurred with low probability when MOC-OHC synapses were stimulated at $1 \mathrm{~Hz}$. However, as the stimulation frequency was raised, the reliability of release increased due to presynaptic facilitation. In addition, the relatively slow decay of eIPSCs gave rise to temporal summation at stimulation frequencies $>10 \mathrm{~Hz}$. The combined effect of facilitation and summation resulted in a frequency-dependent increase in the average amplitude of inhibitory currents in OHCs. Thus, we have demonstrated that short-term plasticity is responsible for shaping MOC inhibition and, therefore, encodes the transfer function from efferent firing frequency to the gain of the cochlear amplifier.

\section{Introduction}

A common feature of all sensory systems is their ability to maximize the sensitivity to specific signals within a noisy background while preserving a wide dynamic range. A strategy to achieve this task is to adapt the gain of the system through feedback circuits depending on the nature and/or salience of the stimulus (Robinson and McAlpine, 2009; Singer et al., 2009). In mammals, sound waves are transmitted to the organ of Corti, the sensory epithelium of the inner ear, where two types of mechanoreceptor, inner hair cells (IHCs) and outer hair cells (OHCs), transform these vibrations into electrical signals. IHCs are the primary phonoreceptors that, upon depolarization by incoming sound, release glutamate and activate the auditory nerve fibers contacting them (Hudspeth, 1997; Fuchs et al., 2003). By virtue of their somatic electromotility, OHCs respond to variations in membrane voltage with changes in their length (Brownell et al., 1985). This

Received Dec. 29, 2010; revised Aug. 22, 2011; accepted Aug. 25, 2011.

Author contributions: J.B., A.B.E.,P.A.F., and E.K. designed research; J.B. performed research; J.B., J.Z.. d.S.M., J.G., and E.K. analyzed data; J.B. and E.K. wrote the paper.

This work was supported by Consejo Nacional de Investigaciones Científicas y Técnicas Grant PIP2005-2007 and National Organization for Hearing Research Grant NOHR 2007 (E.K.), University of Buenos Aires Grants UBACYT X107 2008-2010 (E.K.) and UBACYT M 2008 -2010 (A.B.E.), Agencia Nacional de Promoción Científica y Tecnológica (Argentina) (A.B.E., E.K.), HHMI International Scholars Program (A.B.E.), and NIH Grant R01 DC001508 (P.A.F., A.B.E.).

Correspondence should be addressed to Eleonora Katz, Instituto de Investigaciones en Ingeniería Genética y Biología Molecular, Consejo Nacional de Investigaciones Científicas y Técnicas, Vuelta de Obligado 2490, 1428 Buenos Aires, Argentina. E-mail: ekatz@dna.uba.ar or eleokatz@gmail.com.

DOI:10.1523/JNEUROSCI.6788-10.2011

Copyright $\odot 2011$ the authors $\quad 0270-6474 / 11 / 3114763-12 \$ 15.00 / 0$ causes an enhancement of sound-evoked motion within the cochlear partition that amplifies the input to the IHCs (Ashmore, 2008). The resulting sensitivity and sharp tuning of cochlear afferent fibers is reduced by efferent feedback from the CNS (Wiederhold and Kiang, 1970). OHCs are innervated by cholinergic efferent fibers whose somata are in the medial portion of the superior olivary complex, hence known as the medial olivocochlear (MOC) fibers (Liberman and Brown, 1986). These MOC fibers are the final targets of several feedback loops from both the periphery (Guinan, 1996) and from higher processing centers (Robertson, 2009). MOC neurons activated through these circuits regulate several aspects of auditory processing, including the dynamic range of hearing (Guinan, 1996), the detection of relevant auditory signals (Dolan and Nuttall, 1988; Winslow and Sachs, 1988; Kawase et al., 1993; Maison et al., 2001; Tan et al., 2008), selective attention (Oatman, 1976; Delano et al., 2007), and protection against acoustic trauma (Rajan, 2000; Taranda et al., 2009). Although the importance of the MOC system in hearing is well established, many of the cellular events involved in its function remain unknown. Electrical stimulation of the MOC fibers leads to a reduction of sound-evoked motion in the cochlea (Cooper and Guinan, 2006) and to a decrease in auditory nerve responses, indicating that MOC system reduces the gain of the cochlea through a direct inhibition of $\mathrm{OHC}$ function. Moreover, the strength of cochlear inhibition is proportional to the rate of MOC activity (Galambos, 1956; Wiederhold and Kiang, 1970; Gifford and Guinan, 1987). How this process is orchestrated at the synaptic level is for the most part unknown. The MOC-OHC 
synapse is a peculiar ionotropic inhibitory synapse. It is mediated by acetylcholine (ACh) acting on $\alpha 9 \alpha 10 \mathrm{nAChRs}$ functionally coupled to calcium-activated potassium channels that hyperpolarize the hair cell (Oliver et al., 2000; Elgoyhen and Fuchs, 2010). However, synaptic inhibition of OHCs has not been directly quantified. This is the first report showing postsynaptic responses of OHCs upon electrical stimulation of the MOC fibers. We show that the strength of $\mathrm{OHC}$ inhibition changes with the frequency of MOC activation within their physiological firing range and conclude that short-term plasticity at the MOC-OHC synapse constitutes a mechanism by which OHCs encode MOC firing frequency to adjust the sensitivity of the auditory periphery.

\section{Materials and Methods}

Animal procedures and isolation of the organ of Corti. Procedures for preparing and recording from the postnatal mouse organ of Corti were essentially identical with those previously described (Glowatzki and Fuchs, 2000; Katz et al., 2004; Zorrilla de San Martín et al., 2010). Briefly, apical turns of the organ of Corti were excised from BALB/c mice of either sex between postnatal day 11 (P11) and P13 (day of birth is P0). Mice were used at P11-P13 (around the onset of hearing in altricial rodents) because at this age OHCs are already innervated by the MOC fibers (Pujol et al., 1998; Simmons, 2002) and they can be maintained in vitro for $1-3 \mathrm{~h}$ in healthy conditions. At older ages, recordings become more unreliable due to cell damage soon after the cochlea is excised from the animal. Cochlear preparations were placed in the chamber for electrophysiological recordings, mounted on the stage of a Leica LFS microscope, and viewed with differential interference contrast using a $40 \times$ water-immersion objective and a camera with contrast enhancement (Hamamatsu C275410; Hamamatsu Photonics). All experimental protocols were performed in accordance with the American Veterinary Medical Association's AVMA Guidelines on Euthanasia (June 2007).

Electrophysiological recordings. OHCs were identified by their characteristic shape and their three row arrangement in the organ of Corti. After breaking into the whole-cell configuration, cell capacitance, resting potential, and voltage-dependent currents were monitored in each cell. The cochlear preparation was continuously superfused with an extracellular saline solution of the following composition (in mM): $155 \mathrm{NaCl}, 5.8 \mathrm{KCl}$, $1.3 \mathrm{CaCl}_{2}, 0.7 \mathrm{NaH}_{2} \mathrm{PO}_{4}, 5.6$ D-glucose, and 10 HEPES buffer, pH 7.4. Working solutions containing the different drugs and toxins used were made up in this same saline and applied by a gravity-fed multichannel glass perfusion tube (150 $\mu \mathrm{m}$ tip diameter) positioned $\sim 300 \mu \mathrm{m}$ from the recorded OHC. The recording pipette solution contained the following (in mM): $150 \mathrm{KCl}, 3.5 \mathrm{MgCl}_{2}, 0.1 \mathrm{CaCl}_{2}, 5$ EGTA, 5 HEPES buffer, 2.5 $\mathrm{Na}_{2} \mathrm{ATP}, \mathrm{pH}$ 7.2. In some experiments, to preclude the activation of SK currents by $\mathrm{Ca}^{2+}$, EGTA in the pipette solution was replaced by $10 \mathrm{~mm}$ of the fast calcium chelator 1,2-bis(2-aminophenoxy)ethane- $N, N, N^{\prime}, N^{\prime}$ tetra-acetic acid (BAPTA).

Membrane currents in OHCs from the first row were recorded in the whole-cell patch-clamp mode using an Axopatch 200B amplifier (Molecular Devices), low-pass filtered at $2-10 \mathrm{kHz}$ and digitized at $5-20 \mathrm{kHz}$ with a Digidata 1322A board (Molecular Devices). Unless otherwise stated, recordings were made at room temperature $\left(22-25^{\circ} \mathrm{C}\right)$. In the experiments conducted at higher temperatures $\left(34 \pm 1^{\circ} \mathrm{C}\right)$, both the recording chamber and the extracellular solutions were heated using $\mathrm{RH}-2$ heater blocks and a SH-27B in-line solution heater, respectively, controlled by a TC344B temperature controller (Warner Instruments). Glass recording pipettes, $1.2 \mathrm{~mm}$ inner diameter, had resistances of 6-8 $\mathrm{M} \Omega$. Indicated holding potentials were not corrected for liquid junction potentials $(-4 \mathrm{mV})$. To make the seal and then break into the whole-cell configuration, the recording pipette was always positioned at the midbasal portion of the $\mathrm{OHC}$ under study. In most of the experiments, $\mathrm{OHCs}$ were voltage clamped at a holding voltage of $-40 \mathrm{mV}$ or at $-90 \mathrm{mV}$, when the SK component of the response was minimized by using BAPTA in the intracellular solution.

Electrical stimulation of the MOC efferent axons. Neurotransmitter release was evoked by bipolar electrical stimulation of the medial olivocochlear efferent axons as previously described (Goutman et al., 2005;
Zorrilla de San Martín et al., 2010). Briefly, the electrical stimulus was delivered via a 20 - to $80-\mu \mathrm{m}$-diameter theta glass pipette placed at $20-60$ $\mu \mathrm{m}$ modiolar to the base of the IHC that was aligned with the OHC under study. The position of the pipette was adjusted until postsynaptic currents in the $\mathrm{OHC}$ were consistently activated. An electrically isolated constant current source (model DS3; Digitimer) was triggered via the data acquisition computer to generate pulses up to $30 \mathrm{~mA}, 200-1000 \mu \mathrm{s}$ duration.

Estimation of the quantum content of transmitter release. To obtain the quantum content of transmitter release $(m)$, protocols of 200 stimuli were applied at a frequency of $1 \mathrm{~Hz} . m$ was estimated using three different methods. By the "direct method," $m$ was calculated as the ratio between the mean amplitude of evoked IPSCs (eIPSCs) and the mean amplitude of spontaneous IPSCs (sIPSCs) (Del Castillo and Katz, 1954a). However, the frequency of spontaneous release was very low and several cells could not be included in this analysis. Under the assumption that evoked synaptic events followed a Poisson distribution, $m$ was also calculated by the "method of failures" $\left[m=\ln \left(N / N_{0}\right)\right.$, where $N$ is the total number of stimuli and $N_{0}$ is the number of failures], or as the "coefficient of variation method" ( $m=1 / \mathrm{CV}^{2}$, where $\mathrm{CV}$ is derived from the amplitude distribution of eIPSCs) (Del Castillo and Katz, 1954a).

Paired-pulse protocols. Two consecutive shocks with interstimulus intervals (ISIs) ranging from 4 to $250 \mathrm{~ms}$ were applied 50-100 times. Event detection and amplitude measurements of eIPSCs after each shock were performed manually. The average response $(S)$ after each shock was computed as the sum of all recorded amplitudes divided by the number of repetitions (sweeps). The mean amplitude of evoked events in each pulse $(A)$ was obtained by averaging the amplitudes of all detected eIPSCs. The probability of release $(P)$ was computed as the number of eIPSCs/number of repetitions. For shocks with ISIs of 4 and $10 \mathrm{~ms}$, the maximal response to the first shock could not be discriminated; therefore, the values of the three parameters $(S, P$, and $A$ ) were obtained using a single-shock protocol before the paired-pulse stimulation. The facilitation index for $S, P$, and $A$ was computed as the ratio of their values between the second and the first shock.

Train stimulation protocols. Train stimulation protocols composed of 10 pulses at frequencies ranging from 10 to $80 \mathrm{~Hz}$, were repeated $50-100$ times at intervals of $2 \mathrm{~s}$. For every pulse, the current amplitude $(\Delta I)$ was computed between the baseline and a point taken $10 \mathrm{~ms}$ later. The baseline point was set after the pulse and was adjusted manually depending on the width of the stimulation artifact. The criterion for an eIPSC was $10 \mathrm{pA}$ above baseline ( $\mathrm{rms}$ noise was $2.8 \pm 0.2 \mathrm{pA} ; n=5$ ). The probability of release $(P)$ to each pulse was computed as the number of eIPSCs/number of repetitions (sweeps). The average amplitude $(A)$ was obtained by averaging the eIPSCs amplitude ( $\Delta I$ values) in each pulse. The average response $(S)$ was computed as described in the previous section. To determine the extent of facilitation or depression during a train, values for the parameters $S, P$, and $A$ were normalized to their values at the first pulse. For the average train response, $(I)$ was computed as the difference between baseline before the first pulse and the maximal current after each pulse. The mean accumulated response was obtained by normalizing $(I)$ at the $n$th pulse to its value in the first pulse $\left(I_{n} / I_{1}\right)$.

To determine whether train stimulation protocols exerted long-term effects on synaptic responses, efferent fibers were stimulated with a series of 10 trains at intershock intervals of $1 \mathrm{~Hz}$, with a $60 \mathrm{~s}$ rest period between each series. These series were repeated 10 times to obtain an average value for the responses corresponding to the $n$th train of every series. This control experiment was performed with trains of either 50 or $100 \mathrm{~Hz}$. There were no significant changes in the profile of the responses as the train number increased within the series, showing that the response of each train was independent of its stimulation history. Moreover, the average amplitude of the first pulse in each train was constant, further confirming that there was no change in synaptic strength during the stimulation protocol.

Simulation of high-frequency responses. High-frequency responses were simulated using a representative single-shock response with the baseline set to zero as a template. To simulate temporal summation, individual 1.5 -s-long traces were generated. In each of these individual traces, one eIPSC with a fixed probability of occurrence of 0.25 was added. This is the 


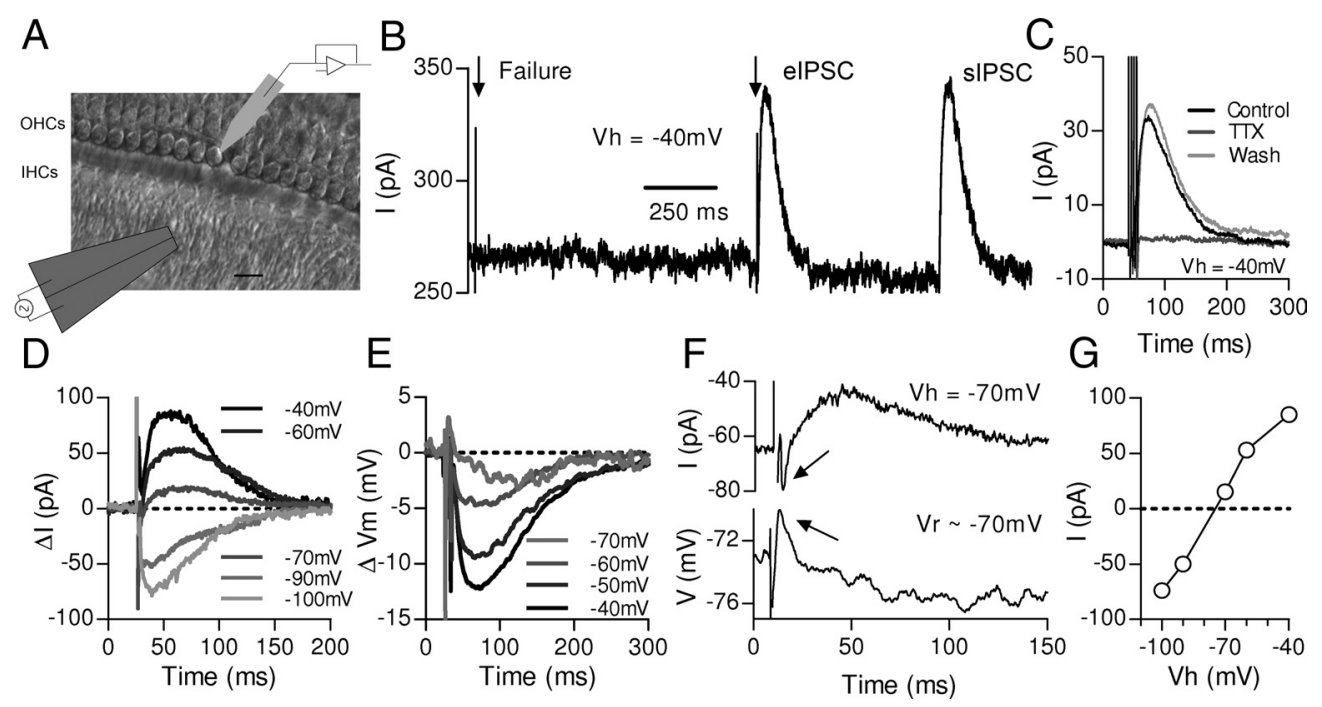

Figure 1. Synaptic responses evoked by electrical stimulation of the MOC efferent fibers in mouse $\mathrm{OHCS}$. $A$, Schematic representation of the experimental setup. $0 \mathrm{HCs}$ from the first row were recorded with a patch pipette while electrical shocks were delivered to the MOC fibers through an extracellular bipolar theta glass pipette positioned $\sim 10-20 \mu \mathrm{m}$ below the IHCs. Scale bar, $10 \mu \mathrm{m} . \boldsymbol{B}$, Representative trace obtained in an OHC in response to two single electrical shocks (arrows). The figure shows one elPSC and one sIPSC, respectively, and also a failure of response upon nerve stimulation. $C$, Preventing the generation of axonal action potentials with $1 \mu \mathrm{m}$ TTX caused a reversible block of the postsynaptic responses evoked by four shocks at $250 \mathrm{~Hz}$. D, Representative traces of single-shock-evoked IPSCs in OHCs held at membrane voltages ranging from -40 to $-100 \mathrm{mV}$. E, IPSPs obtained in the same cell in the current-clamp configuration. The holding $\left(V_{h}\right)$ and the membrane $\left(V_{m}\right)$ voltages are indicated in $\boldsymbol{D}$ and $\boldsymbol{E}$, respectively. Note that, at $V_{h}$ negative to $-80 \mathrm{mV}$, IPSCs are completely inward, while positive to $-80 \mathrm{mV}$ a slow outward current develops in addition to the fast inward component (D). These outward currents are mirrored by hyperpolarizing responses in the current-clamp configuration $(\boldsymbol{E}) . \ln \boldsymbol{F}$, more detailed traces of the biphasic response are shown in the voltage-clamp configuration at a $V_{\mathrm{h}}$ of $-70 \mathrm{mV}$ (top panel) and in the current-clamp configuration (bottom panel) starting from a resting potential of approximately $-73 \mathrm{mV}$. The arrows indicate the fast inward/depolarizing phase of the two components of the synaptic response. $\boldsymbol{G}, I-V$ curve obtained plotting peak IPSCs amplitudes versus $V_{\mathrm{h}}$ in the cell illustrated in $\boldsymbol{D}$.

probability of success observed at a stimulation frequency of $1 \mathrm{~Hz}$ (single-shock probability) (see Results, Quantum content of transmitter release at the MOC-OHC synapse) (see Fig. 7A, Summation). To simulate a response taking into account the effect of facilitation (see Fig. 7A, Summation and Facilitation), the same procedure was applied but in each pulse the added eIPSC had a probability of occurrence that was computed as the initial probability of release $(0.25)$ multiplied by the change in this probability $(P)$ extracted from Figure $5 F$ data. The increase in current $\left(I_{n} / I_{1}\right)$ in the simulated traces was then calculated as described in the previous section.

Data analysis. Spontaneous and evoked synaptic currents (both singleshock and paired-pulse) were identified by eye and analyzed using Mini Analysis 6.0.3 (Synaptosoft). Decay and rise time $\left(\tau_{\text {decay }}\right.$ and $\left.\tau_{\text {rise }}\right)$ values were fitted with monoexponential functions. Train responses were analyzed using either Clampfit 10.2 (MDS Analytical Technologies) or custom-made routines built with MATLAB R2008b (MathWorks). MATLAB was also used to simulate train responses. Further analysis and graph editing was performed with Prism 5 (GraphPad Software). Unless otherwise stated, data are expressed as the mean \pm SEM.

Drugs and toxins. Stock solutions of strychnine- $\mathrm{HCl}, 3$-tropanylindole-3-carboxylate hydrochloride (ICS-205930-HCl), apamin, iberiotoxin, and tetrodotoxin were prepared in distilled water, stored in aliquots at $-20^{\circ} \mathrm{C}$, and diluted in the extracellular solution just before use. All drugs were purchased from Sigma-Aldrich.

\section{Results}

Biophysical and pharmacological properties of synaptic responses in $\mathrm{OHCs}$ evoked by electrical stimulation of the MOC efferent fibers

Whole-cell voltage-clamp recordings were made in OHCs from P11-P13 acutely isolated apical turns of mouse organs of Corti. Bipolar electrical stimulation in the modiolar region (Fig. 1A) evoked IPSCs in OHCs voltage clamped at $-40 \mathrm{mV}$ (Fig. $1 B$ ). These evoked synaptic currents were completely and reversibly prevented by $1 \mu \mathrm{M}$ tetrodotoxin (TTX), a voltage-gated sodium current blocker (Fig. 1C), thus confirming that eIPSCs were in- deed produced by transmitter release evoked by action potentials in the MOC fibers. When OHCs were voltage clamped at holding potentials $\left(V_{\text {hold }}\right.$ ) between -100 and $-80 \mathrm{mV}$, IPSCs were inward, whereas at $V_{\text {hold }}$ positive to $-80 \mathrm{mV}$ they included a fast inward and a slow outward component (Fig. $1 D ; F$, top panel). Two components were also observed in voltage recordings. A fast depolarizing phase was followed by a slower hyperpolarization that became larger as the membrane was depolarized (Fig. 1E; F, bottom panel). The current-voltage $(I-V)$ relationship of peak eIPSC amplitude was almost linear between -100 and $-40 \mathrm{mV}$ and had a reversal potential of $-75 \mathrm{mV}$ (Fig. $1 G$ ), a value that is close to the equilibrium potential for potassium under our recording conditions $\left(E_{\mathrm{K}}=-82 \mathrm{mV}\right)$. The biphasic nature of the IPSCs, and the reversal potential are consistent with those of ACh-evoked currents in chicken short hair cells (Fuchs and Murrow, 1992) and in mammalian IHCs (Glowatzki and Fuchs, 2000; Gómez-Casati et al., 2005) and OHCs (Housley and Ashmore, 1991; Dulon and Lenoir, 1996; Evans, 1996; Nenov et al., 1996a,b; Oliver et al., 2000).

In mammalian cochlear hair cells, the fast depolarizing phase of the cholinergic response is mediated by the $\alpha 9 \alpha 10$ nicotinic receptor (Elgoyhen et al., 2001; Sgard et al., 2002; Katz et al., 2004; Gómez-Casati et al., 2005; Goutman et al., 2005; Vetter et al., 2007). This nicotinic receptor is highly permeable to $\mathrm{Ca}^{2+}$ (Weisstaub et al., 2002; Gómez-Casati et al., 2005) and produces the opening of SK2 calcium-activated potassium channels to hyperpolarize the hair cell (Dulon and Lenoir, 1996; Nenov et al., 1996a; Glowatzki and Fuchs, 2000; Oliver et al., 2000; Marcotti et al., 2004; Gómez-Casati et al., 2005; Goutman et al., 2005). Evoked IPSCs in OHCs were completely blocked by the application of two specific $\alpha 9 \alpha 10$ antagonists, strychnine (300 nM) and ICS-205930 (300 nM) (Rothlin et al., 1999, 2003; Elgoyhen et al., 2001) (Fig. 2A,B). In addition, the SK channel-specific antago- 

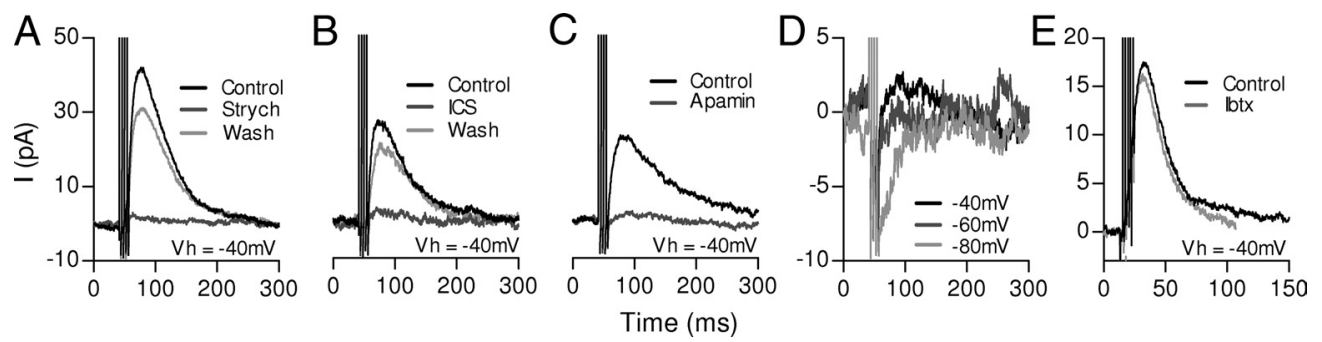

Figure 2. Pharmacological characteristics of IPSCs in OHCS. IPSCs in OHCs were reversibly blocked by the $\alpha 9 \alpha 10 \mathrm{nAChR}$ antagonists strychnine (300 nM) (A) and ICS-205930 (300 nm) (B). C, Application of the $S K$ channel-specific antagonist, apamin $(100 \mathrm{~nm})$, blocked the outward component of the inhibitory response at a $V_{\mathrm{h}}$ of $-40 \mathrm{mV}$. $\boldsymbol{D}$, Responses in the presence of apamin are shown at $V_{\mathrm{h}}$ of $-40,-60$, and $-80 \mathrm{mV}$. Note that, at -60 and $-80 \mathrm{mV}$, the remaining cholinergic inward component can still be observed. E, lberiotoxin (100 nm), a specific and irreversible BK channel antagonist, had no effect on elPSCs at $-40 \mathrm{mV}$. In all cases, responses were evoked by four shocks at $250 \mathrm{~Hz}$. Traces are the average responses to 20 stimuli in each condition: control, after local application of the drug (perfusion times ranging from 10 to $150 \mathrm{~s}$ depending on the drug) and after washing the preparation for $200 \mathrm{~s}$.

Table 1. The quantum content of transmitter release at the $\mathrm{MOC}-\mathrm{OHC}$ synapse

\begin{tabular}{|c|c|c|c|c|c|c|c|c|c|c|}
\hline & \multicolumn{3}{|l|}{ Kinetic constants } & \multicolumn{4}{|c|}{ IPSCs mean amplitude (pA) } & \multicolumn{3}{|l|}{ Quantum content $(m)$} \\
\hline & $\tau$ rise $20-80 \%$ (ms) & $\tau$ decay $10-90 \%$ (ms) & $n$ & sIPSCs & $n$ & elPSCs & $n$ & (1) Mean elPSC/mean sIPSC & (2) $\ln \left(N / N_{0}\right)$ & (3) $1 / \mathrm{CV}^{2}$ \\
\hline 1 & $11.8 \pm 4.0$ & $56.7 \pm 21.3$ & 238 & $58 \pm 18$ & 285 & $34 \pm 16$ & 48 & 0.05 & 0.07 & 0.06 \\
\hline 2 & $14.4 \pm 5.6$ & $67.6 \pm 22.1$ & 35 & $59 \pm 21$ & 40 & $99 \pm 48$ & 276 & 1.15 & 1.17 & 1.25 \\
\hline 3 & $14.1 \pm 4.9$ & $58.0 \pm 21.8$ & 173 & $52 \pm 25$ & 201 & $62 \pm 38$ & 188 & 0.48 & 0.51 & 0.41 \\
\hline 4 & $9.2 \pm 3.6$ & $44.0 \pm 14.3$ & 88 & $47 \pm 21$ & 119 & $35 \pm 21$ & 103 & 0.14 & 0.21 & 0.16 \\
\hline 5 & $10.3 \pm 3.8$ & $41.2 \pm 12.2$ & 48 & $48 \pm 23$ & 54 & $51 \pm 30$ & 116 & 0.11 & 0.14 & 0.11 \\
\hline 6 & $12.3 \pm 4.0$ & $49.2 \pm 14.8$ & 57 & $35 \pm 17$ & 68 & $28 \pm 14$ & 40 & 0.03 & 0.05 & 0.04 \\
\hline 7 & $11.2 \pm 3.5$ & $32.3 \pm 8.7$ & 31 & $28 \pm 15$ & 133 & $39 \pm 25$ & 285 & 0.31 & 0.23 & 0.17 \\
\hline 8 & $17.2 \pm 6.6$ & $60.4 \pm 22.6$ & 70 & $42 \pm 20$ & 117 & $39 \pm 23$ & 68 & 0.21 & 0.26 & 0.20 \\
\hline Mean $\pm S D$ & $12.6 \pm 2.6$ & $51.2 \pm 11.6$ & & $46.1 \pm 10.8$ & & $48.4 \pm 23.1$ & & $0.31 \pm 0.37$ & $0.35 \pm 0.37$ & $0.31 \pm 0.40$ \\
\hline
\end{tabular}

elPSCs were evoked by stimulation at $1 \mathrm{~Hz}$, while sIPSCs were recorded in the absence of stimulation. In the first two rows, $20-80 \%$ rise time and $10-90 \%$ decay time for the sIPSCs are shown, while the fourth and sixth rows show the mean amplitude of eIPSCs and sIPSCs, respectively, for eight OHCs. In each cell, the quantum content $(m)$ was estimated in three different ways: (1) dividing the mean elPSC amplitude (including failures in the mean) by the mean sIPSC amplitude (direct method); (2) by the rate of failures, with $m=\ln \left(N / N_{0}\right)$, where $N$ is the number of electrical stimuli and $N_{0}$ is the number of failures (method of failures); or (3) by the coefficient of variation (CV) method, with $m=1 / \mathrm{CV}^{2}$. Values are the mean \pm SD.

nist, apamin (Köhler et al., 1996), nearly completely blocked the outward component of eIPSCs at $-40 \mathrm{mV}$ (Fig. 2C), while the inward isolated cholinergic current was still observed at $-80 \mathrm{mV}$ (Fig. 2D). These results confirm that the eIPSCs observed in OHCs resulted from the known above-mentioned postsynaptic mechanism. It has been suggested (Rüttiger et al., 2004) and recently proven (Wersinger et al., 2010) that another $\mathrm{Ca}^{2+}$ activated $\mathrm{K}$ channel, the BK channel, specifically contributes to the cholinergic response of OHCs in the midbasal, but not apical cochlear turns. In the present study, iberiotoxin, a BK channelspecific antagonist (Galvez et al., 1990), had no effect on either the amplitude or time course of IPSCs at $-40 \mathrm{mV}$ (Fig. 2E) in these apical turn $\mathrm{OHCs}$, consistent with the specific role of $\mathrm{BK}$ channels only in basal OHCs.

\section{Quantum content of transmitter release at the MOC-OHC synapse}

Voltage-clamp recordings were performed at $-40 \mathrm{mV}$, close to the resting potential of the OHCs $(-51.5 \pm 10.2 \mathrm{mV} ; n=34$ OHCs). This allowed stable whole-cell recordings and a good signal-to-noise ratio (Fig. $1 B$ ) of the outward-going (SKdependent) synaptic currents. In this condition, sIPSCs had a rise time $(20-80 \%)$ of $12.6 \pm 2.6 \mathrm{~ms}$ and a decay time $(10-90 \%)$ of $51.2 \pm 11.6 \mathrm{~ms}(n=8$ OHCs; Table 1$)$. Evoked IPSCs had similar waveforms (Fig. $1 B$ ). The amplitudes of both spontaneous and evoked IPSCs ranged between 10 and $250 \mathrm{pA}$, with mean values of $46.1 \pm 10.8$ (sIPSCs) and $48.4 \pm 23.1 \mathrm{pA}$ (eIPSCs) $(n=8$ OHCs; Table 1). To verify that sIPSCs were indeed spontaneous events, and not produced by spontaneous firing of the MOC efferent fibers, the amplitude distribution of sIPSCs was obtained in the absence or the presence of $1 \mu \mathrm{M}$ TTX. No differences were found between these conditions (Fig. $3 A, C$ ), indicating that spontaneous events were due to the action potential-independent fusion of vesicles to the presynaptic plasma membrane.

Postsynaptic responses evoked with single shocks at a stimulation frequency of $1 \mathrm{~Hz}$ had a low success rate $\left(P_{\text {success }}=0.25 \pm 0.06 ; n=\right.$ 18 OHCs). Quantum content $(m)$ of transmitter release, that is, the mean number of vesicles released by each presynaptic action potential (Del Castillo and Katz, 1954a), was obtained using three different approaches. With the direct method, $m$ was calculated dividing the mean eIPSC amplitude upon $1 \mathrm{~Hz}$ stimulation by the mean sIPSC amplitude in every cell (Table 1). In addition, given the low probability of release observed at the MOC-OHC synapse, synaptic events should follow a Poisson distribution (Del Castillo and Katz, 1954a). Under this assumption, the quantum content of evoked release was obtained using the failures $\left[m=\ln \left(N / N_{0}\right)\right]$ and the coefficient of variation methods $\left(m=1 / \mathrm{CV}^{2}\right)$ (see Materials and Methods and Table 1). Estimations of $m$ for eight $\mathrm{OHCs}$ yielded values that were consistent across the three methods (Table 1), ranging from 0.03 to 1.15 . Notwithstanding, the possibility of occurrence of response failures during the protocol due to stimulus failures should be considered as they would lead to an underestimation of the quantum content of transmitter release. To test whether failures could be due to conduction failures, we evaluated the effect of increasing the concentration of extracellular $\mathrm{Ca}^{2+}$ on the percentage of observed failures. An increase in the concentration of divalent ions decreases axon excitability due to surface charge effects (Dodge and Rahamimoff, 1967). Therefore, if the observed failures were caused by conduction failures, their rate should increase upon raising the extracel- 

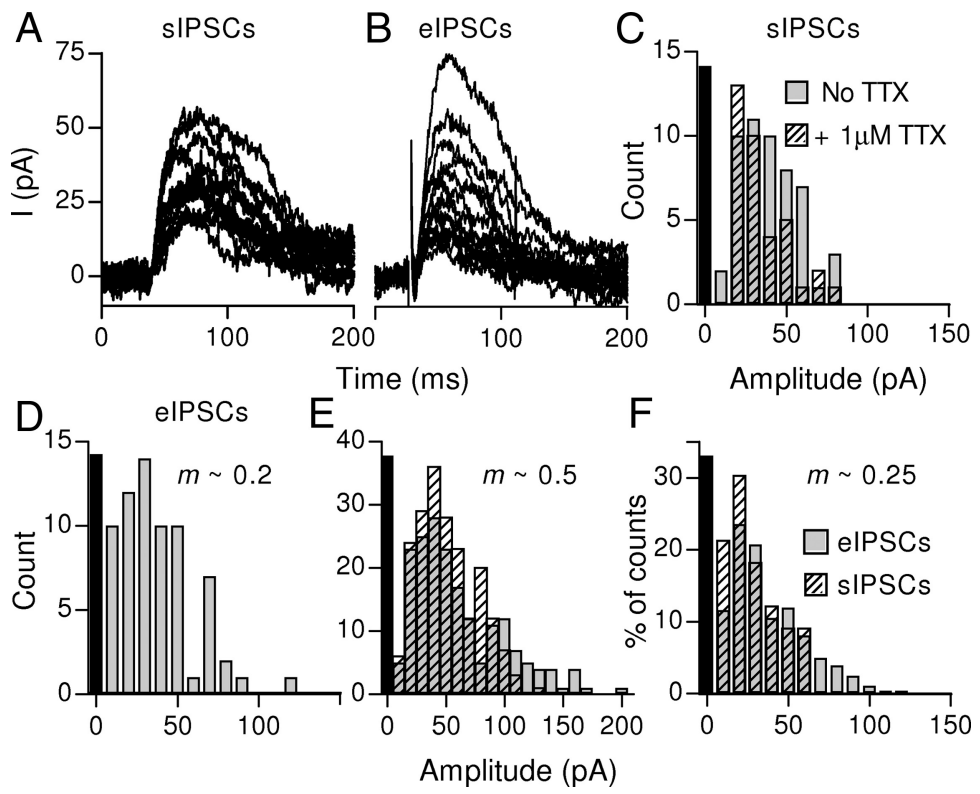

Figure 3. Amplitude distributions of spontaneous and evoked IPSCS. Representative traces of spontaneous synaptic currents (sIPSCS) in the presence of $1 \mu \mathrm{M}$ TTX (15 events) $(\boldsymbol{A})$ and evoked synaptic currents (eIPSCS) elicited by single electrical shocks (15 events) ( $\boldsymbol{B}$ ). The amplitude histograms corresponding to the cell recorded in $\boldsymbol{A}$ and $\boldsymbol{B}$ are shown in $\boldsymbol{C}$ and $D$, respectively. Note that there are no differences in the amplitude distribution of sIPSCs in the presence (gray bars) or absence (striped bars) of TTX (C).E, $\boldsymbol{F}$, eIPSCs (gray bars) and sIPSCS (striped bars) amplitude histograms are shown for two $\mathrm{OHCs}$. In $\boldsymbol{C}-\boldsymbol{F}$, the black bars indicate noise floor.

lular $\mathrm{Ca}^{2+}$ concentration. Conversely, if failures were indeed release failures, they should decrease upon raising the extracellular $\mathrm{Ca}^{2+}$ concentration. Postsynaptic responses evoked with single shocks at a stimulation frequency of $1 \mathrm{~Hz}$ were recorded in OHCs. Upon changing the extracellular $\mathrm{Ca}^{2+}$ concentration from 1.3 to $2 \mathrm{mM}$, the number of failures was significantly reduced by $32 \pm 9 \%(n=3 \mathrm{OHCs})$. This result together with the consistency in the $m$ value obtained by the three different methods used to evaluate it, suggests that the incidence of stimulus failures is not significant.

In agreement with the low quantum content of transmitter release at this synapse, the amplitude distribution of spontaneous and evoked responses for these cells overlapped (Fig. $3 E, F$ ). If one accepts that spontaneous currents are due to the fusion of a single vesicle, these results indicate that most of the evoked events were composed of single quanta. Consistent with this view, larger events that might consist of two or three quanta were rare (Fig. $3 A-E)$. This reinforces the idea that stimulation failures do not account for the low quantum content observed at this synapse.

However, it is worth noticing that the sIPSCs histograms were skewed (Fig. 3C,D). From the eight analyzed OHCs, five presented non-normal distributions (D'Agostino and Pearson normality test, $p<0.01$ ) with skewness ranging from 0.6 to 1.4 . The fact that sIPSCs (uniquantal) distributions resulted in seemingly multiquantal histograms (Jonas et al., 1993) precluded the analysis of evoked amplitude histograms to obtain an $m$ value. Asymmetrical histograms for spontaneous synaptic currents have been described in several CNS synapses (Bekkers et al., 1990; Jonas et al., 1993; Bekkers, 1994) and are generally attributed to variability among different release sites (Auger and Marty, 2000). Despite the variability and asymmetry in sIPSCs distributions, we can conclude that MOC-OHC synapses have a low probability of release at $1 \mathrm{~Hz}$.

\section{Paired-pulse facilitation at the MOC-OHC synapse}

Synapses with low quantum content tend to facilitate upon high-frequency stimulation (Debanne et al., 1996; Murthy et al., 1997; Zucker and Regehr, 2002) as observed for efferent synapses on turtle auditory hair cells (Art et al., 1984) and neonatal rat inner hair cells (Goutman et al., 2005). To characterize plasticity at the MOC-OHC synapse, the average response was measured for paired pulses with ISIs ranging from 4 to $250 \mathrm{~ms}$ (Fig. $4 A-D)$. The facilitation index $\left(\mathrm{FI}_{S}\right)$ was defined as the ratio $S_{2} / S_{1}$, where $S_{1}$ and $S_{2}$ are the average responses of the $\mathrm{OHC}$ to the first and the second pulse, respectively. $\mathrm{FI}_{S}$ values $>1$ indicate facilitation, while $\mathrm{FI}_{\mathrm{S}}<1$ indicate depression (Del Castillo and Katz, 1954b; Mallart and Martin, 1967; Katz and Miledi, 1968; Goutman et al., 2005). For eight $\mathrm{OHCs}$, facilitation was observed at ISIs of 10 and $25 \mathrm{~ms}\left(\mathrm{FI}_{S}=2.1 \pm 1.1\right.$ at $10 \mathrm{~ms}$ and $1.6 \pm 0.6$ at $25 \mathrm{~ms}$, respectively; $n=8$ OHCs; $p<0.05$, one-sample $t$ test; Fig. $4 E$ ). No statistically significant plasticity was found for shorter or longer ISIs.

In most synapses, the short-term enhancement of the postsynaptic response has been shown to be a presynaptic process that causes an increase in the number of quanta released in subsequent pulses (Zucker and Regehr, 2002). However, given that transmitter release was measured at $-40 \mathrm{mV}$, where the response is dominated by the secondary activation of the SK2 channel following $\mathrm{Ca}^{2+}$ entry through the $\alpha 9 \alpha 10$ nAChR (Gómez-Casati et al., 2005), a postsynaptic component cannot be overlooked. If the increase in the response was solely due to a postsynaptic effect, there should be an increase in the amplitude of successfully evoked IPSCs without variations in the probability of release. Conversely, if the increase in the postsynaptic response was due to an increase in the number of quanta released by each action potential, there should be a reduction in the number of failures of release upon nerve stimulation. To distinguish between these two possibilities, the facilitation index was calculated separately as the amplitude of the successfully evoked postsynaptic responses $\left(\mathrm{FI}_{A}=A_{2} / A_{1}\right)$ and the probability of release $\left(\mathrm{FI}_{P}=P_{2} / P_{1}\right)$. No significant effect was found on the $\mathrm{FI}_{A}$ at all ISIs evaluated $(n=8$ OHCs; $p>0.5$, one-sample $t$ test; Fig. $4 E$ ), whereas a significant increase was found for $\mathrm{FI}_{P}$ at ISIs of 10 and $25 \mathrm{~ms}\left(\mathrm{FI}_{P}=2.2 \pm 0.9\right.$ and $1.6 \pm 0.6$ for ISIs of 10 and $25 \mathrm{~ms}$, respectively; $n=8$ OHCs; $p<0.05$, one-sample $t$ test; Fig. $4 E$ ). Facilitation indexes for the three parameters (average response, $\mathrm{FI}_{S}$, amplitude, $\mathrm{FI}_{A}$, and probability, $\mathrm{FI}_{P}$ ) were plotted in the same graph (Fig. $4 E$ ). These results indicate that facilitation of the averaged postsynaptic responses (Fig. $4 E$ ) can be accounted for entirely by an increase in the probability of release. Therefore, at the MOC-OHC synapse facilitation in response to highfrequency stimulation is of presynaptic origin.

\section{Facilitation and summation contribute to $\mathrm{OHC}$ inhibition during repetitive stimulation of MOC efferents} MOC fibers fire regularly at frequencies ranging from 1 to $120 \mathrm{~Hz}$ in vivo (Robertson and Gummer, 1985; Liberman and Brown, 1986; Brown, 1989) and cochlear inhibition increases with the 

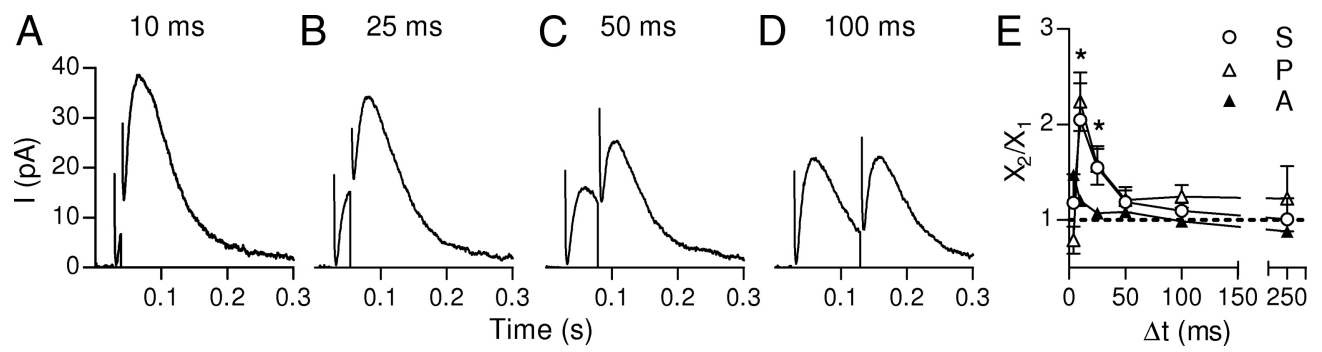

Figure 4. Postsynaptic responses in $0 H C$ f facilitate upon paired-pulse stimulation of the MOC fibers. $A-D$, Representative traces of average IPSCs evoked by a pair of pulses with ISIs ranging from 4 through $100 \mathrm{~ms}\left(50-100\right.$ repetitions). E, Facilitation indexes for the elPSC average amplitude $\left(S_{2} / S_{1}\right)$, the probability of occurrence of an event $\left(P_{2} / P_{1}\right)$, and the average amplitude of successfully evoked IPSCs $\left(A_{2} / A_{1}\right)$ as a function of the ISI. Facilitation indexes for each parameter were calculated as the value obtained in the second stimulus with respect to the first one. Note that the facilitation index calculated using either $S$ or $P$ overlap in almost all ISIs tested. ${ }^{*} p<0.05$, one-sample $t$ test.

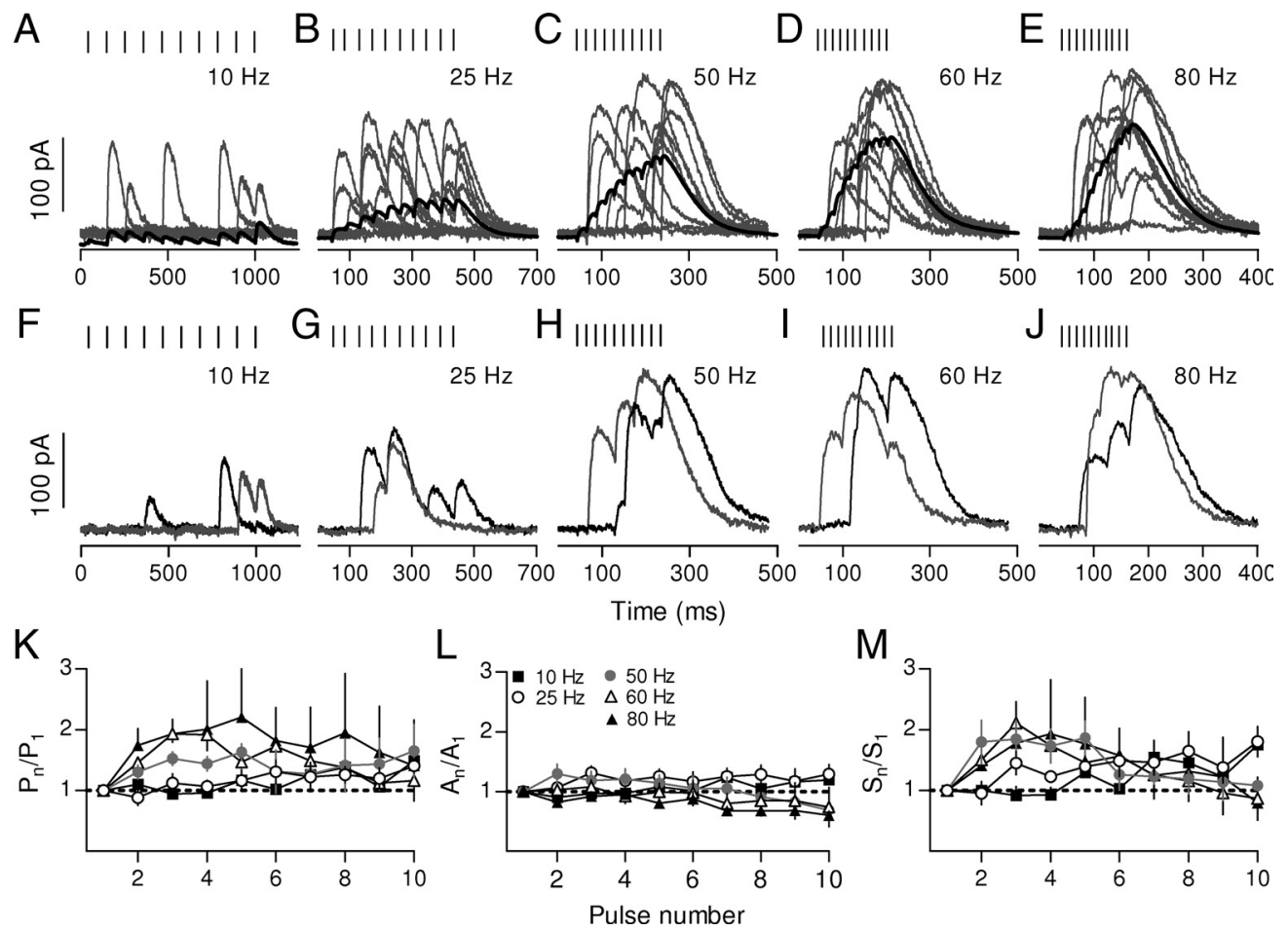

Figure 5. Facilitation of transmitter release contributes to the increase in the postsynaptic response during high-frequency stimulation. $\boldsymbol{A}-\boldsymbol{E}$, Representative traces of 10 individual responses to 10 shock trains (gray traces) applied at different frequencies. The black trace is the average response of 100 repetitions at each frequency. Note that, at high frequencies, responses at the end of the train become larger. $\boldsymbol{F}-J$, Individual traces of responses to 10 shock trains showing summation of consecutive IPSCs. The probability of release $(P)$, the elPSCS average amplitude $(A)$, and the average response $(S)$ were computed for every pulse during 10 shock trains at frequencies ranging from 10 to $80 \mathrm{~Hz}$. In $\boldsymbol{K}-\boldsymbol{M}$, the normalized mean values for these parameters at the different stimulation frequencies are plotted versus the pulse number ( $n=3-110 \mathrm{HCS})$. Note that, at high frequencies, there is an increase in $P$ during the first shocks $(\boldsymbol{K})$, while the amplitude of the elPSCs remains stable $(\boldsymbol{L})$.

frequency of MOC fiber activation (Galambos, 1956; Wiederhold and Kiang, 1970; Gifford and Guinan, 1987). The postsynaptic effect of repetitive efferent activity was examined using trains of 10 shocks at frequencies ranging from 10 to $80 \mathrm{~Hz}$ (corresponding to ISIs of 100 to $12.5 \mathrm{~ms}$ ). Representative responses of OHCs to these trains are illustrated in Figure 5. Synaptic events occurred sparsely at $10 \mathrm{~Hz}$ but increased in frequency as stimulation frequency increased. In addition, the amplitude of individual responses appeared to increase at high MOC activation frequencies (Fig. $5 C-E$ ). These two effects combined to increase the average postsynaptic currents as the frequency of stimulation increased (Fig. 5, black traces). In current-clamp recordings, a sustained and enhanced hyperpolarization of the OHCs was observed in response to high-frequency MOC stimulation (Fig. 6).

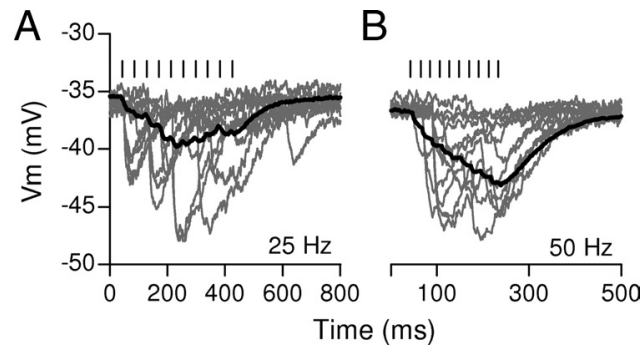

Figure 6. IPSPs obtained in $\mathrm{OHCS}$ in response to 25 and $50 \mathrm{~Hz}$ stimulation trains. $\boldsymbol{A}, \boldsymbol{B}$, Representative traces of 10 individual responses, obtained in $\mathrm{OHCs}$ in the current-clamp configuration, to 10 shock trains (gray traces) applied at $25(\boldsymbol{A})$ and $50 \mathrm{~Hz}(\boldsymbol{B})$. The black trace is the average response obtained upon 100 repetitions of the train. 

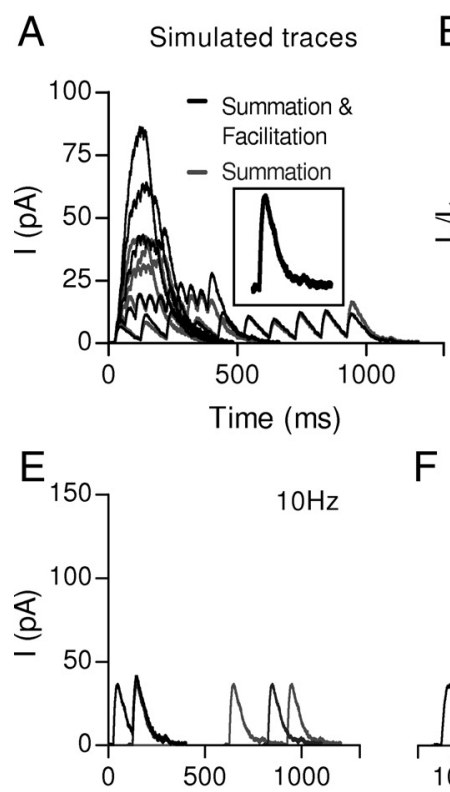

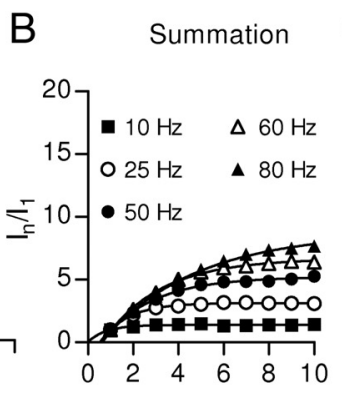

$\mathrm{F}$

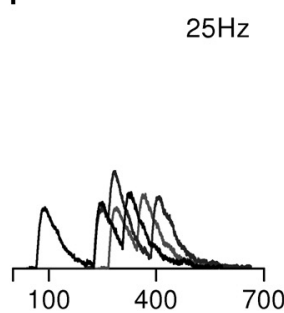

C Summation \& Facilitation

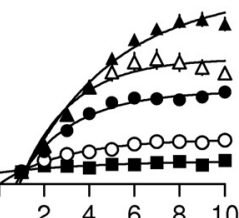

Pulse number
D Experimental Data
G

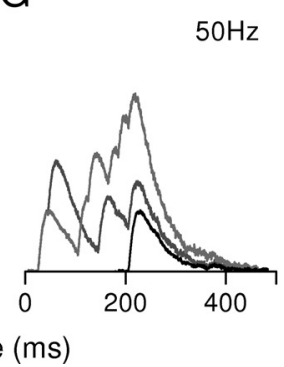

$\mathrm{H}$

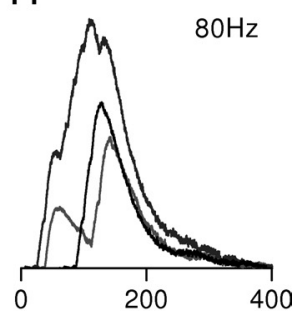

Figure 7. Summation also contributes to the increment of the postsynaptic response during high-frequency stimulation. To estimate the effect of summation during high-frequency stimulation, simulated responses were constructed from a single-shock response ( $\boldsymbol{A}$, inset) considering only temporal summation (gray traces) or considering facilitation by also taking into account the change in the probability of release (black traces) for every shock (the change in $P$ values was obtained from experiments illustrated in Fig. $5 F$ ). Plots of normalized current versus pulse number were constructed from the simulation considering only summation $(\boldsymbol{B})$ or summation and facilitation (C).D, Plot of normalized current versus pulse number derived from the experimental data shown in Figure 5. $\boldsymbol{E}-\boldsymbol{H}$, Representative traces of the simulated single sweep responses are shown. In each panel, the simulated frequency is indicated.

Facilitation during repetitive stimulation was assessed by measuring the probability of release $(P)$ and the average amplitude of the successfully evoked responses $(A)$ (Fig. $5 K, L ; n=$ 3-11 OHCs) for each successive stimulus. The total averaged response $(S)$ was computed as the sum of the evoked responses divided by the number of stimulation trains (Fig. $5 M$ ). Consistent with the paired-pulse experiments, an increase in the probability of release $(P)$ was observed when trains of shocks were applied at frequencies ranging from 50 to $80 \mathrm{~Hz}$ (ISIs of 20 to 12.5 $\mathrm{ms})$. No effect on this parameter was found for lower frequencies ( 10 or $25 \mathrm{~Hz}$; ISIs of 100 and $40 \mathrm{~ms}$, respectively). The increase in $P$ was maximal during the first shocks $(p<0.001$, one-way ANOVA for the third pulse) and this was accompanied by an increase in the average response (Fig. $5 M$ ). At the end of the train, there was no significant difference in $P$ across stimulation frequencies ( $p>0.05$, one-way ANOVA for the 10th pulse) (Fig. $5 K)$. There were no significant changes in the amplitude of evoked responses for the different frequencies throughout the train, although a trend toward decreased amplitude was apparent at the higher frequencies (Fig. $5 L ; p>0.05$, one-way ANOVA for the 3 rd and 10th pulse).

Since IPSC duration is longer than the ISIs of high-frequency trains (Table 1, Fig. 5), summation of consecutive evoked currents probably contributes to the amplitude of the response during high-frequency stimulation (Chen et al., 2002). In fact, summation of IPSCs was observed in single-trial experiments (Fig. 5F-J). The relative contribution of summation was evaluated by simulating the postsynaptic responses at different stimulation frequencies. A representative IPSC evoked by a single shock was used for building simulated trains (Fig. 7, inset). Temporal summation was modeled considering a constant probability of release $(P)$ of 0.25 for each pulse (Fig. $7 A$, light traces), while facilitation was incorporated by multiplying $P$ by a factor that takes into account its change as calculated from the experiments illustrated in Figure $5 \mathrm{~K}$ (Fig. $7 \mathrm{~A}$, dark traces). Representative traces of single-trial simulated responses for different frequencies are shown in Figure $7 E-H$. The accumulated response as a function of pulse number is plotted for frequencies ranging between 10 and $80 \mathrm{~Hz}$ for "Summation" (Fig. $7 B$ ) or "Summation and Facilitation" (Fig. 7C). The relative increase in OHC total currents for the different stimulation frequencies was calculated using the responses recorded in the OHCs illustrated in Figure 5 (Fig. 7D; $n=3-11 \mathrm{OHCs}$ ). Exponential fits provided maximum response increments (except for a linear fit to $10 \mathrm{~Hz}$ data) that grew as a function of stimulus frequency $(4.2 \pm 0.3,7.5 \pm 0.8$, $12.4 \pm 0.7,21.6 \pm 5.9$ for $25,50,60$, and $80 \mathrm{~Hz}$, respectively; $n=$ 3-11 OHCs; Fig. 7D). Summation and facilitation combined to produce a response function most closely resembling the experimental data (plateau levels: $3.1 \pm 0.1,5.2 \pm 0.2,6.7 \pm 0.3$, and $8.8 \pm 0.5$ for $25,50,60$, and $80 \mathrm{~Hz}$, respectively, for Summation, and 3.6 $\pm 0.2,7.4 \pm 0.3,10.0 \pm 0.4$, and $15.4 \pm 0.7$ for 25, 50, 60, and $80 \mathrm{~Hz}$, respectively, for Summation and Facilitation; Fig. $7 B, C)$. These data show that both facilitation and summation contribute to $\mathrm{OHC}$ inhibition during repetitive activation of the MOC fibers.

As stated above, the fact that the increase in the postsynaptic response during repetitive stimulation correlates with an increase in the probability of release and not with an increase in the mean amplitude of IPSCs, strongly suggests that facilitation is due to a presynaptic mechanism. However, at the MOC-OHC synapse, IPSCs are mediated by the activation of the $\alpha 9 \alpha 10 \mathrm{nAChR}$ and the subsequent activation of SK2 channels. These SK2 channels are activated both by $\mathrm{Ca}^{2+}$ entry through the nAChR (Oliver et al., 2000; Gómez-Casati et al., 2005) and possibly by $\mathrm{Ca}^{2+}$ released from nearby subsynaptic cisterns (Lioudyno et al., 2004). Therefore, in the following set of experiments, we minimized the activation of SK2 channels by buffering postsynaptic $\mathrm{Ca}^{2+}$ with BAPTA in the recording pipette (see Materials and Methods), to 


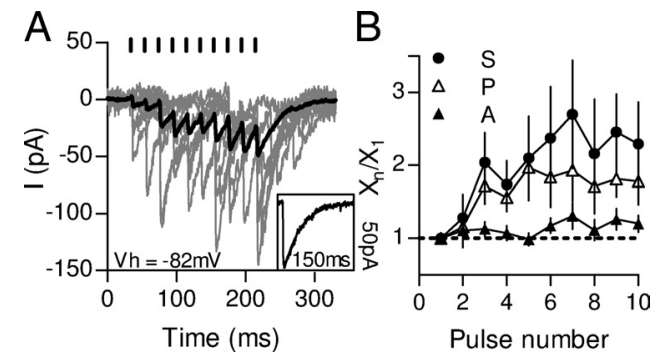

Figure 8. Facilitation of transmitter release is still observed in the absence of SK2 channel activation. Responses in $\mathrm{OHCs}$ recorded at a $V_{\mathrm{h}}$ of $-82 \mathrm{mV}$ with an intracellular solution containing $10 \mathrm{~mm}$ of the fast calcium chelator, BAPTA, to minimize the activation of SK2 channels. In $A$, representative traces of 10 individual responses to 10 shock trains (gray traces) applied at $50 \mathrm{~Hz}$. The black trace is the average response of 50 repetitions. An average response to a single shock (1 Hz stimulation frequency) is shown in the inset. The probability of release $(P)$, the elPSCs average amplitude $(A)$, and the average response $(S)$ were computed for every pulse during the 10 shock trains. In $\boldsymbol{B}$, the normalized mean values for these parameters are plotted versus the pulse number ( $n=70 \mathrm{HCs})$.

evaluate whether the strengthening of transmission observed upon high-frequency stimulation was independent from the accumulation of $\mathrm{Ca}^{2+}$ at the postsynaptic cell. To see a measurable response in the absence of the SK2 current, OHCs were held at $-82 \mathrm{mV}$. Under these conditions, IPSCs mean amplitude was $-43 \pm 2 \mathrm{pA}$ with a $20-80 \%$ rise time constant of $2.4 \pm 0.4 \mathrm{~ms}$ and a $10-90 \%$ decay time constant of $29 \pm 1 \mathrm{~ms}$ (60 events, 7 $\mathrm{OHCs})$. To evaluate the degree of facilitation under this experimental condition, 25-100 repetitions of 10 shock stimulation trains at $50 \mathrm{~Hz}$ were applied (Fig. $8 \mathrm{~A}$ ). The probability of release $(P)$, the average amplitude $(A)$, and the average response $(S)$ were computed for every pulse. As observed with the combined (nAChR plus SK) responses at $-40 \mathrm{mV}$ (Fig. 5), upon highfrequency stimulation of the MOC fibers, there was an increase in the isolated (nAChR) average postsynaptic responses at $-82 \mathrm{mV}$ $(S)$ that correlated with an increase in the probability of release $(P)(p<0.05$, one-sample $t$ test for the third pulse), with no changes in their amplitude $(A)(n=7$ OHCs; Fig. 8). These results show that facilitation of transmitter release at the MOC$\mathrm{OHC}$ synapse can occur independently of frequency-dependent changes in SK current in the postsynaptic hair cell.

It has been reported that inhibition of auditory function by MOC activity lasts for as long as MOC fibers are stimulated and then decays within hundreds of milliseconds (Wiederhold and Kiang, 1970; Guinan, 1996). It was therefore of interest to ask whether the MOC-OHC synapse can sustain release during prolonged stimulation. To this end, MOC efferent fibers were stimulated at $50 \mathrm{~Hz}$ for $1 \mathrm{~s}$ with an intertrain interval of $30 \mathrm{~s}$. The averaged current increased in all $\mathrm{OHCs}$ tested, reaching a plateau with a time constant of $101.9 \pm 10.4 \mathrm{~ms}(n=3)$. This plateau level did not decrease significantly during the stimulation period (Fig. $9 A$ ). In addition, frequent spontaneous activity appeared after the stimulation ended (Fig. 9B), extending the postsynaptic effect for $200-500 \mathrm{~ms}$ (Fig. 9A). These results indicate that the MOC$\mathrm{OHC}$ synapse is able to sustain synaptic activity for long periods.

\section{Effects of temperature on the properties of synaptic transmission at the MOC-OHC synapse}

All the results presented in the previous sections were conducted at room temperature. Therefore, it is possible that at physiological temperatures some of the processes there described could be affected. To evaluate the effect of temperature on synaptic transmission at the MOC-OHC synapse, evoked IPSCs were measured near physiolog-
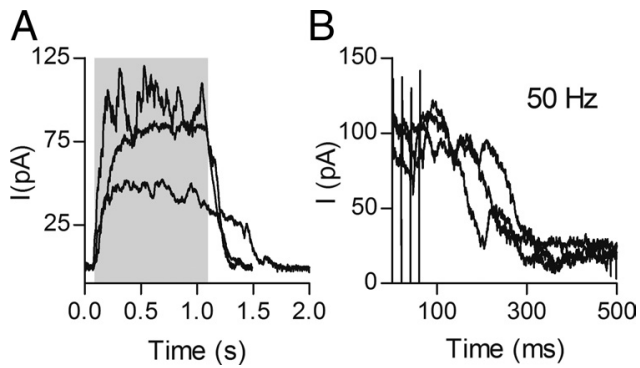

Figure 9. Sustained release at the $\mathrm{MOC}-\mathrm{OHC}$ synapse during long trains of stimulation. $\boldsymbol{A}$, Average currents obtained in three different $0 \mathrm{HCs}$ in response to a $50 \mathrm{~Hz}$ train applied for $1 \mathrm{~s}$ (10-50 sweeps were averaged in each cell). The shaded region indicates the time interval of the stimulus. Stimulus artifacts were removed for clarity. Note that the average current remains almost constant during the stimulation period and that it does not return to baseline immediately after the end of the stimulus. The rise time constant of the current was $101.9 \pm 10.4 \mathrm{~ms}$ $(n=3)$ and the decay time was variable, ranging from 200 to $500 \mathrm{~ms}$. $\boldsymbol{B}$, Individual traces of after-stimulus activity.

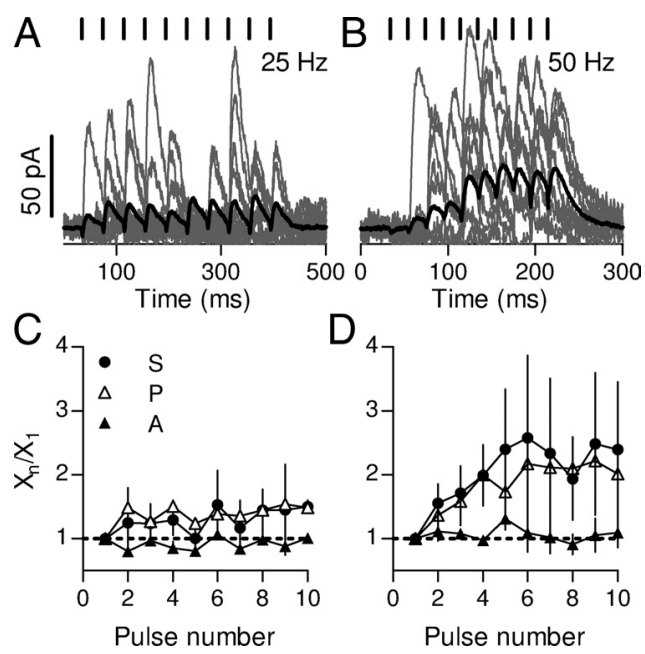

Figure 10. Effects of temperature on facilitation. $\boldsymbol{A}, \boldsymbol{B}$, Representative traces of 10 individual responses, obtained near physiological temperature (PT) $\left(34 \pm 1^{\circ} \mathrm{C}\right.$ ), to 10 shock trains (gray traces) applied at different frequencies. The black trace is the average response of 50 repetitions at each frequency. The probability of release $(P)$, the eIPSCs average amplitude $(A)$, and the average response ( $S$ ) were computed for every pulse during 10 shock trains. In $\boldsymbol{C}$ and $\boldsymbol{D}$, the normalized mean values for these parameters are plotted versus the pulse number for 25 ( $\boldsymbol{C}$; $n=20 \mathrm{HCs}$ ) and $50 \mathrm{~Hz}(D ; n=30 \mathrm{HCs})$ stimulation frequencies. Note that, at $50 \mathrm{~Hz}$, there is an increase in $P$ and $S$ along the train $(\boldsymbol{D})$, whereas at $25 \mathrm{~Hz}$ these values remain stable $(\boldsymbol{C})$.

ical temperature. The increase in temperature caused a twofold decrease in both the rise and decay constants of single-shock evoked IPSCs $\left(\tau_{\text {rise }} 20-80 \%: 5 \pm 0.5 \mathrm{~ms} ; \tau_{\text {decay }} 10-90 \%: 25 \pm 5 \mathrm{~ms} ; n=\right.$ 4 OHCs; see Fig. 11A). There were no effects of temperature, however, in the mean amplitude of synaptic currents $(56 \pm 17$ $\mathrm{pA} ; n=4$ OHCs).

Another synaptic process that could be sensitive to temperature is facilitation (Eccles et al., 1941; Atluri and Regehr, 1996; Klyachko and Stevens, 2006). To analyze the effects of temperature on the facilitation index, 10 shock trains at frequencies of 25 and $50 \mathrm{~Hz}$ were applied to cochlear preparations maintained at $34^{\circ} \mathrm{C}$ (Fig. $\left.10 A, B\right)$. The total average response $(S)$, the probability of release $(P)$, and the mean response $(A)$ were calculated for each pulse. As observed at room temperature, there was no increase in any of the parameters at a stimulation frequency of 25 $\mathrm{Hz}$ (Fig. 10C). However, when the frequency of stimulation was raised to $50 \mathrm{~Hz}$, an increase in the probability of release $(1.6 \pm$ 0.4 -fold at the third pulse with respect to the first pulse; $n=3$ 

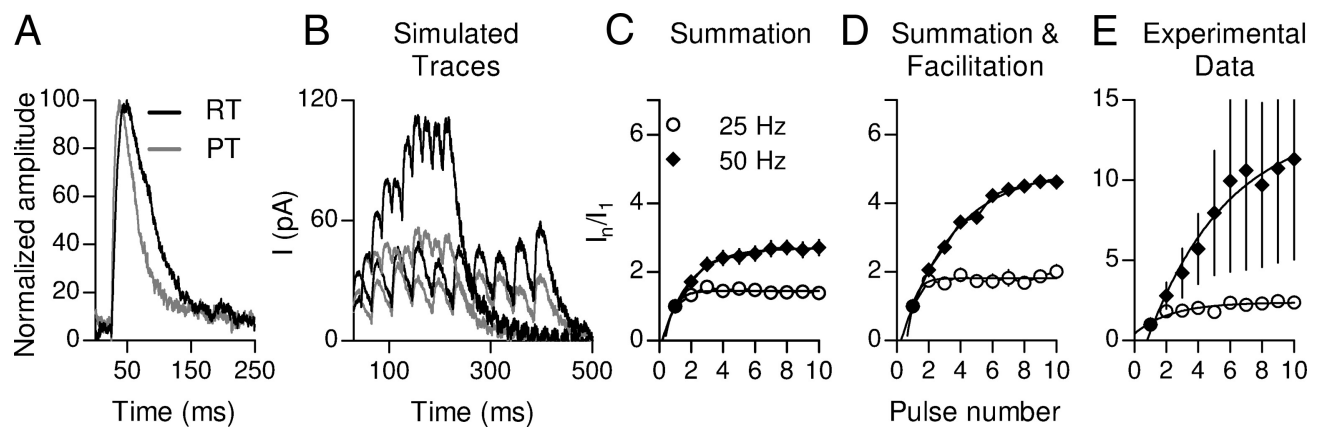

Figure 11. Effects of temperature on summation of postsynaptic responses. $\boldsymbol{A}$, Representative IPSCs recorded at room temperature (RT) $\left(\sim 24^{\circ} \mathrm{C}\right)$ and at a near physiological temperature $(\mathrm{PT})$ $\left(34 \pm 1^{\circ} \mathrm{C}\right)$. To estimate the effects of temperature on summation during high-frequency stimulation, simulated responses were constructed from a single-shock response at $34^{\circ} \mathrm{C}(\boldsymbol{A}$, gray trace) considering only temporal summation ( $\boldsymbol{B}$, gray traces) or considering facilitation by also taking into account the change in the probability of release ( $\boldsymbol{B}$, black traces) for every shock (the change in $P$ values was obtained from the experiments illustrated in Fig. $10 C, D)$. Plots of normalized current versus pulse number were constructed from the simulation considering only Summation $(C)$ or Summation and Facilitation (D).E, Plot of normalized current versus pulse number derived from the experimental data shown in Figure 10.

OHC) accompanied by an increase in the average response (1.7 \pm 0.4 -fold at the third pulse with respect to the first pulse; $n=3$ $\mathrm{OHC}$ ) was observed (Fig. 10D). The magnitude of this change was similar to that found at room temperature (Fig. 5). This result shows that facilitation of transmitter release at the MOC$\mathrm{OHC}$ synapse is not sensitive to variations in temperature within the range tested. Moreover, we found no significant changes in the initial probability of release at $34^{\circ} \mathrm{C}\left(P_{\text {success }}=0.26 \pm 0.1 ; n=\right.$ 3 OHCs) compared with that obtained at room temperature, and consequently, there were no differences in the mean quantum content $(0.27 \pm 0.08$ and $0.33 \pm 0.11$ as computed by the CV and failure methods, respectively; $n=3$ OHCs).

We have previously shown that summation contributes to the increase in postsynaptic responses as a function of stimulation frequency, and that this effect is related to the slow time constant of the postsynaptic responses (Fig. $5 F-J$ ). Therefore, to evaluate whether the changes in the kinetics of IPSCs found at physiological temperatures affected the degree of summation during highfrequency stimulation, we used the model described above to reconstruct responses at 25 and $50 \mathrm{~Hz}$ in the presence and absence of facilitation. For this, we used a representative singleshock trace and the change in probability calculated in Figure 10 (Fig. 11A). As expected, the faster kinetics of IPSCs diminished the effect of summation on the increase in the average currents during trains. The maximal response increments in the Summation simulation were lower than those found at room temperature (plateau levels: $1.40 \pm 0.03$ and $2.7 \pm 0.1$ for 25 and $50 \mathrm{~Hz}$, respectively; Fig. $11 C$, Summation). When facilitation was included in the simulation, the maximal response increment was not affected at $25 \mathrm{~Hz}$, but it increased twofold for the $50 \mathrm{~Hz}$ simulations (plateau levels: $1.8 \pm 0.1$ and $5.0 \pm 0.2$ for 25 and 50 $\mathrm{Hz}$, respectively; Fig. $11 \mathrm{D}$, Summation and Facilitation). Similar results were found when the increase in current was calculated for the experimental data (plateau levels: $2.4 \pm 0.1$ and $13.7 \pm 9.4$ for $25, n=2 \mathrm{OHCs}$, and $50 \mathrm{~Hz}, n=3 \mathrm{OHCs}$, respectively; Fig. $11 \mathrm{E}$, Experimental Data). Together, these results show that at physiological temperatures summation, although still significant at 50 $\mathrm{Hz}$ (Fig. $11 \mathrm{~B}$ ), is reduced at the lower stimulation frequency as a consequence of the faster kinetics of IPSCs. Facilitation, however, presented no significant differences with that observed at room temperature at both stimulation frequencies.

\section{Discussion}

This work is the first to describe synaptic transmission at the mammalian MOC-OHC synapse evoked by electrical stimula- tion of the MOC efferent fibers. We show that the MOC-OHC synapse has a low resting probability of release. However, presynaptic facilitation combined with postsynaptic summation significantly increase the reliability and strength of synaptic transmission during repetitive efferent activity. This is consistent with the strengthening of the MOC effect on auditory function observed in vivo upon increasing the frequency of efferent activity (Galambos, 1956; Wiederhold and Kiang, 1970; Brown and Nuttall, 1984; Gifford and Guinan, 1987) and shows that plasticity of the MOC-OHC synapse might determine the efficacy of MOC feedback to serve as the "gain control" of the auditory periphery.

\section{Characteristics of the MOC-OHC synapse}

The biophysical and pharmacological characteristics of eIPSCs in $\mathrm{OHCs}$ resemble those previously described for cholinergic currents elicited by the application of ACh to isolated mammalian OHCs (Dulon and Lenoir, 1996; Evans, 1996; Nenov et al., 1996a,b) and for spontaneous synaptic currents in OHCs from acutely isolated mouse organ of Corti (Oliver et al., 2000). This further supports the notion that the inhibitory sign of the MOC$\mathrm{OHC}$ cholinergic synapse is due to $\mathrm{Ca}^{2+}$ entry through $\alpha 9 \alpha 10$ $\mathrm{nAChRs}$ and the subsequent gating of calcium-activated SK2 potassium channels (Nenov et al., 1996b; Oliver et al., 2000). This "two-channel" cholinergic inhibitory synapse clearly differs from the usual ionotropic inhibition of GABAergic or glycinergic synapses (Moss and Smart, 2001). The unique features of the hair cell efferent synapse make it a valuable model to study the molecules and mechanisms involved in this unusual type of cholinergic transmission.

The overlap between the sIPSCs and eIPSCs amplitude histograms suggests that, on average, only one vesicle is released upon arrival of an action potential. In mice, the OHCs from the apical region are usually innervated by only one efferent fiber (Maison et al., 2003). In addition, one efferent axon only rarely makes more than one contact with each OHC (Wilson et al., 1991; Warr and Boche, 2003). Therefore, only one bouton will be activated each time an electrical shock is applied. The fact that amplitude histograms of sIPSCs were non-Gaussian could indicate the existence of variability among release sites as in CNS synapses (Jonas et al., 1993; Bekkers, 1994; Auger and Marty, 2000). Moreover, variability in the postsynaptic response amplitude at each active site (measured as SK current) could arise from the coupling between $\alpha 9 \alpha 10$ nAChRs and the SK2 channels (Oliver et al., 2000; Katz et al., 2004), as well as in the calcium-induced calcium re- 
lease from postsynaptic cisterns proposed to contribute to SK channel activation (Yoshida et al., 1994; Lioudyno et al., 2004).

The poor efficacy of synaptic transmission at the MOC-OHC synapse is reflected by the low quantum content of transmitter release $(m=0.31 \pm 0.37)$ when eliciting single action potentials at a frequency of $1 \mathrm{~Hz}$. This value is similar to that reported for the transient rat and mouse MOC-IHC synapses $(m=1 \pm 0.5)$ (Goutman et al., 2005; Zorrilla de San Martín et al., 2010). The fact that this high rate of failures decreases upon increasing the extracellular $\mathrm{Ca}^{2+}$ concentration indicates that the unreliability of transmitter release at the MOC-OHC synapse is mainly due to the stochastic nature of release, rather than to axonal threshold variations or conduction failures (Allen and Stevens, 1994). At the transient mouse MOC-IHC synapse, it has been shown that coupling between L-type voltage-gated calcium channels and BK channels functions as a negative-feedback loop to decrease synaptic output (Zorrilla de San Martín et al., 2010). Therefore, this mechanism could contribute to the low initial probability of release at the MOC-OHC synapse.

Although there is no detailed description of the MOC efferent bouton ultrastructure, electron micrographs of hair cell synapses from different species show that efferent endings have a large number of synaptic vesicles (Lenoir et al., 1980; Nadol, 1988; Simmons et al., 1996; Bruce et al., 2000). What proportion of these vesicles makes up release sites is still unknown, but these results suggest that vesicle availability is not a limiting factor for release (Schikorski and Stevens, 1997; Xu-Friedman and Regehr, 2004). Conversely, the fact that release can be sustained for prolonged stimulation periods is consistent with the high density of synaptic vesicles in MOC boutons. Moreover, the fact that synaptic output at the MOC-OHC synapse significantly increases when the MOC fibers are stimulated at high rates further supports the hypothesis that vesicle availability is not the limiting factor. The strengthening of transmission is accounted for by both facilitation and summation of OHCs synaptic responses. Facilitation is due to an increase in the probability of release and is therefore of presynaptic origin. The effect of summation on synaptic output is accounted for by the long decay times of the combined nAChR and SK2 IPSCs. This notion is further supported by the fact that, despite the faster kinetics of IPSCs at physiological temperatures, summation still contributes to the increment in the postsynaptic responses at high frequencies of stimulation.

\section{Functional consequences of short-term plasticity at the MOC-OHC synapse in auditory function}

Despite differences in structure among vertebrate auditory organs, the main function of the efferent system is conserved among species: namely, to inhibit hair cells and thereby regulate the dynamic range of hearing (Art and Fettiplace, 1984; Guinan, 1996). Furthermore, some characteristics of efferent physiology are also quite similar. For example, a low resting level of release and facilitation of responses during high-frequency firing was found in the turtle papilla (Art et al., 1984) and at the transient efferent synapse to mammalian IHCs (Goutman et al., 2005). The present work shows that these properties also apply to MOC synapses on OHCs, the final targets of MOC efferent fibers in adult mammals (Simmons, 2002). Conservation of these synaptic mechanisms suggests they play an important role in the control of auditory function.

Synapses with low initial probability of release and strong facilitation have been postulated to work as high-pass filters (Fortune and Rose, 2001), responding best to high-frequency activity

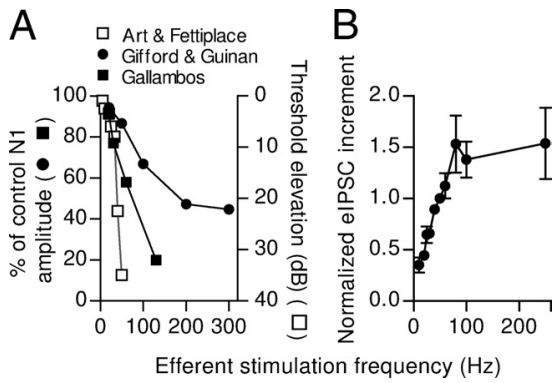

Figure 12. Dependence of afferent function and the inhibitory responses of $\mathrm{OHC}$ on the frequency of efferent stimulation. $A$, Relationship between the frequency of $\mathrm{MOC}$ activation and inhibition of afferent activity in the cat [adapted from the studies by Galambos (1956) and Gifford and Guinan (1987)] and in the turtle [adapted from the study by Art and Fettiplace (1984)]. In the left $y$-axis efferent effect was quantified as the ratio between the amplitude of the $\mathrm{N} 1$ component of the compound action potential (CAP) produced by moderate sound stim-

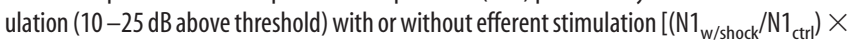
100] (Galambos, 1956; Gifford and Guinan, 1987). The right $y$-axis shows the increase in sound intensity (threshold shift in decibels) necessary to evoke an afferent discharge as a function of the efferent stimulation frequency (Art and Fettiplace, 1984). $\boldsymbol{B}$, Increment in eIPSC amplitudes (mean \pm SEM) after 10 shocks of efferent stimulation at different frequencies. Due to data variability, the values from different cells were normalized to the increment in the amplitude of the response at a stimulation frequency of $50 \mathrm{~Hz}$. Note that, in both afferent activity $(\boldsymbol{A})$ and eIPSCS of $\mathrm{OHC}(\boldsymbol{B})$, there is a range of frequencies where there is a linear relationship between the frequency of $\mathrm{MOC}$ activation and the increment in inhibition.

(Lisman, 1997). In the context of the mammalian auditory system, such a mechanism could allow OHCs to ignore spontaneous or infrequent MOC activity and establish a "threshold" for cochlear suppression. Moreover, summation and facilitation at the MOC-OHC synapse provide the additional benefit of scaling inhibition according to the frequency of MOC activity, thus finetuning cochlear amplification. This is particularly relevant since, in vivo, MOC fibers fire regularly but with variable frequencies (Robertson and Gummer, 1985; Liberman and Brown, 1986; Brown, 1989). In addition, it has been shown that, when MOC fibers are activated by sound (the MOC reflex), their firing frequencies are indeed modulated by stimulus properties such as intensity, origin (monoaural or binaural), or type (noise, tone) (Brown et al., 1998), and that efferent firing frequency increases linearly with sound intensity (Robertson and Gummer, 1985; Liberman and Brown, 1986; Brown, 1989; Brown et al., 1998). Therefore, short-term plasticity of the MOC-OHC synapse is relevant for encoding graded levels of efferent feedback.

Several characteristics of the MOC-OHC synapse correlate with results from in vivo studies of the MOC effect on auditory function. Thus, brainstem electrical stimulation of MOC neurons relies on high-frequency trains rather than single shocks to inhibit auditory function (Galambos, 1956; Wiederhold and Kiang, 1970; Mountain, 1980; Gifford and Guinan, 1987). Similarly, responses in $\mathrm{OHCs}$ rely on facilitation and summation to reach maximal inhibition. Moreover, it has been reported that, when high-frequency trains are applied to MOC neurons, the maximal inhibitory effect is attained after a few hundred milliseconds and that, upon shutting off the stimulus, the response decays to resting levels with the same delay (Wiederhold and Kiang, 1970). Likewise, summed IPSCs rise to a peak within 100$200 \mathrm{~ms}$ and usually decay over an equivalent interval. In addition, the strength of the efferent effect increases as the frequency of efferent stimulation increases, not only in mammals (Galambos, 1956; Wiederhold and Kiang, 1970; Brown and Nuttall, 1984; Gifford and Guinan, 1987) but also in other vertebrates (Flock and Russell, 1973; Art and Fettiplace, 1984) (Fig. 12A). As for 
these in vivo studies, the magnitude of $\mathrm{OHC}$ inhibition rises linearly with the frequency of efferent activation, saturating near $100 \mathrm{~Hz}$ (Fig. 12 B). Finally, the increase of MOC firing rate with sound intensity (Robertson and Gummer, 1985; Brown, 1989; Brown et al., 1998) would lead to a greater gain reduction and is consistent with the hypothesis that one role of the MOC system is to protect from acoustic trauma (Rajan, 2000; Taranda et al., 2009). The consistency between in vivo physiological experiments and the present data suggests that the dynamics of the MOC-OHC synapse is indeed shaping cochlear responses to efferent inhibition.

\section{References}

Allen C, Stevens CF (1994) An evaluation of causes for unreliability of synaptic transmission. Proc Natl Acad Sci U S A 91:10380-10383.

Art JJ, Fettiplace R (1984) Efferent desensitization of auditory nerve fibre responses in the cochlea of the turtle Pseudemys scripta elegans. J Physiol 356:507-523.

Art JJ, Fettiplace R, Fuchs PA (1984) Synaptic hyperpolarization and inhibition of turtle cochlear hair cells. J Physiol 356:525-550.

Ashmore J (2008) Cochlear outer hair cell motility. Physiol Rev 88:173-210.

Atluri PP, Regehr WG (1996) Determinants of the time course of facilitation at the granule cell to Purkinje cell synapse. J Neurosci 16:5661-5671.

Auger C, Marty A (2000) Quantal currents at single-site central synapses. J Physiol 526:3-11.

Bekkers JM (1994) Quantal analysis of synaptic transmission in the central nervous system. Curr Opin Neurobiol 4:360-365.

Bekkers JM, Richerson GB, Stevens CF (1990) Origin of variability in quantal size in cultured hippocampal neurons and hippocampal slices. Proc Natl Acad Sci U S A 87:5359-5362.

Brown MC (1989) Morphology and response properties of single olivocochlear fibers in the guinea pig. Hear Res 40:93-109.

Brown MC, Nuttall AL (1984) Efferent control of cochlear inner hair cell responses in the guinea-pig. J Physiol 354:625-646.

Brown MC, Kujawa SG, Duca ML (1998) Single olivocochlear neurons in the guinea pig. I. Binaural facilitation of responses to high-level noise. J Neurophysiol 79:3077-3087.

Brownell WE, Bader CR, Bertrand D, de Ribaupierre Y (1985) Evoked mechanical responses of isolated cochlear outer hair cells. Science 227:194-196.

Bruce LL, Christensen MA, Warr WB (2000) Postnatal development of efferent synapses in the rat cochlea. J Comp Neurol 423:532-548.

Chen C, Blitz DM, Regehr WG (2002) Contributions of receptor desensitization and saturation to plasticity at the retinogeniculate synapse. Neuron 33:779-788.

Cooper NP, Guinan JJ Jr (2006) Efferent-mediated control of basilar membrane motion. J Physiol 576:49-54.

Debanne D, Guérineau NC, Gähwiler BH, Thompson SM (1996) Pairedpulse facilitation and depression at unitary synapses in rat hippocampus: quantal fluctuation affects subsequent release. J Physiol 491:163-176.

Del Castillo J, Katz B (1954a) Quantal components of the end-plate potential. J Physiol 124:560-573.

Del Castillo J, Katz B (1954b) Statistical factors involved in neuromuscular facilitation and depression. J Physiol 124:574-585.

Delano PH, Elgueda D, Hamame CM, Robles L (2007) Selective attention to visual stimuli reduces cochlear sensitivity in chinchillas. J Neurosci 27:4146-4153.

Dodge FA Jr, Rahamimoff R (1967) Co-operative action a calcium ions in transmitter release at the neuromuscular junction. J Physiol 193: $419-432$.

Dolan DF, Nuttall AL (1988) Masked cochlear whole-nerve response intensity functions altered by electrical stimulation of the crossed olivocochlear bundle. J Acoust Soc Am 83:1081-1086.

Dulon D, Lenoir M (1996) Cholinergic responses in developing outer hair cells of the rat cochlea. Eur J Neurosci 8:1945-1952.

Eccles JC, Katz B, Kuffler SW (1941) Nature of the "endplate potential" in curarized muscle. J Neurophysiol 4:362-387.

Elgoyhen AB, Fuchs PA (2010) Efferent innervation and function. In: The Oxford handbook of auditory science: the ear (Fuchs PA, ed), pp 283-306. Oxford: Oxford UP.

Elgoyhen AB, Vetter DE, Katz E, Rothlin CV, Heinemann SF, Boulter J
(2001) alpha10: a determinant of nicotinic cholinergic receptor function in mammalian vestibular and cochlear mechanosensory hair cells. Proc Natl Acad Sci U S A 98:3501-3506.

Evans MG (1996) Acetylcholine activates two currents in guinea-pig outer hair cells. J Physiol 491:563-578.

Flock A, Russell IJ (1973) The post-synaptic action of efferent fibres in the lateral line organ of the burbot Lota lota. J Physiol 235:591-605.

Fortune ES, Rose GJ (2001) Short-term synaptic plasticity as a temporal filter. Trends Neurosci 24:381-385.

Fuchs PA, Murrow BW (1992) Cholinergic inhibition of short (outer) hair cells of the chick's cochlea. J Neurosci 12:800-809.

Fuchs PA, Glowatzki E, Moser T (2003) The afferent synapse of cochlear hair cells. Curr Opin Neurobiol 13:452-458.

Galambos R (1956) Suppression of auditory nerve activity by stimulation of efferent fibers to cochlea. J Neurophysiol 19:424-437.

Galvez A, Gimenez-Gallego G, Reuben JP, Roy-Contancin L, Feigenbaum P, Kaczorowski GJ, Garcia ML (1990) Purification and characterization of a unique, potent, peptidyl probe for the high conductance calciumactivated potassium channel from venom of the scorpion Buthus tamulus. J Biol Chem 265:11083-11090.

Gifford ML, Guinan JJ Jr (1987) Effects of electrical stimulation of medial olivocochlear neurons on ipsilateral and contralateral cochlear responses. Hear Res 29:179-194.

Glowatzki E, Fuchs PA (2000) Cholinergic synaptic inhibition of inner hair cells in the neonatal mammalian cochlea. Science 288:2366-2368.

Gómez-Casati ME, Fuchs PA, Elgoyhen AB, Katz E (2005) Biophysical and pharmacological characterization of nicotinic cholinergic receptors in rat cochlear inner hair cells. J Physiol 566:103-118.

Goutman JD, Fuchs PA, Glowatzki E (2005) Facilitating efferent inhibition of inner hair cells in the cochlea of the neonatal rat. J Physiol 566:49-59.

Guinan JJ Jr (1996) Physiology of olivocochlear efferents. In: The cochlea (Dallos P, Popper AN, Fay RR, eds), pp 435-502. New York: Springer.

Housley GD, Ashmore JF (1991) Direct measurement of the action of acetylcholine on isolated outer hair cells of the guinea pig cochlea. Proc Biol Sci 244:161-167.

Hudspeth AJ (1997) How hearing happens. Neuron 19:947-950.

Jonas P, Major G, Sakmann B (1993) Quantal components of unitary EPSCs at the mossy fibre synapse on CA3 pyramidal cells of rat hippocampus. J Physiol 472:615-663.

Katz B, Miledi R (1968) The role of calcium in neuromuscular facilitation. J Physiol 195:481-492.

Katz E, Elgoyhen AB, Gómez-Casati ME, Knipper M, Vetter DE, Fuchs PA, Glowatzki E (2004) Developmental regulation of nicotinic synapses on cochlear inner hair cells. J Neurosci 24:7814-7820.

Kawase T, Delgutte B, Liberman MC (1993) Antimasking effects of the olivocochlear reflex. II. Enhancement of auditory-nerve response to masked tones. J Neurophysiol 70:2533-2549.

Klyachko VA, Stevens CF (2006) Temperature-dependent shift of balance among the components of short-term plasticity in hippocampal synapses. J Neurosci 26:6945-6957.

Köhler M, Hirschberg B, Bond CT, Kinzie JM, Marrion NV, Maylie J, Adelman JP (1996) Small-conductance, calcium-activated potassium channels from mammalian brain. Science 273:1709-1714.

Lenoir M, Shnerson A, Pujol R (1980) Cochlear receptor development in the rat with emphasis on synaptogenesis. Anat Embryol (Berl) 160:253-262.

Liberman MC, Brown MC (1986) Physiology and anatomy of single olivocochlear neurons in the cat. Hear Res 24:17-36.

Lioudyno M, Hiel H, Kong JH, Katz E, Waldman E, Parameshwaran-Iyer S, Glowatzki E, Fuchs PA (2004) A "synaptoplasmic cistern" mediates rapid inhibition of cochlear hair cells. J Neurosci 24:11160-11164.

Lisman JE (1997) Bursts as a unit of neural information: making unreliable synapses reliable. Trends Neurosci 20:38-43.

Maison S, Micheyl C, Collet L (2001) Influence of focused auditory attention on cochlear activity in humans. Psychophysiology 38:35-40.

Maison SF, Adams JC, Liberman MC (2003) Olivocochlear innervation in the mouse: immunocytochemical maps, crossed versus uncrossed contributions, and transmitter colocalization. J Comp Neurol 455:406-416.

Mallart A, Martin AR (1967) An analysis of facilitation of transmitter release at the neuromuscular junction of the frog. J Physiol 193:679-694.

Marcotti W, Johnson SL, Kros CJ (2004) A transiently expressed SK current 
sustains and modulates action potential activity in immature mouse inner hair cells. J Physiol 560:691-708.

Moss SJ, Smart TG (2001) Constructing inhibitory synapses. Nat Rev Neurosci 2:240-250.

Mountain DC (1980) Changes in endolymphatic potential and crossed olivocochlear bundle stimulation alter cochlear mechanics. Science 210: $71-72$.

Murthy VN, Sejnowski TJ, Stevens CF (1997) Heterogeneous release properties of visualized individual hippocampal synapses. Neuron 18: $599-612$.

Nadol JB Jr (1988) Comparative anatomy of the cochlea and auditory nerve in mammals. Hear Res 34:253-266.

Nenov AP, Norris C, Bobbin RP (1996a) Acetylcholine response in guinea pig outer hair cells. I. Properties of the response. Hear Res 101:132-148.

Nenov AP, Norris C, Bobbin RP (1996b) Acetylcholine response in guinea pig outer hair cells. II. Activation of a small conductance $\mathrm{Ca}^{2+}$-activated $\mathrm{K}^{+}$channel. Hear Res 101:149-172.

Oatman LC (1976) Effects of visual attention on the intensity of auditory evoked potentials. Exp Neurol 51:41-53.

Oliver D, Klöcker N, Schuck J, Baukrowitz T, Ruppersberg JP, Fakler B (2000) Gating of $\mathrm{Ca}^{2+}$-activated $\mathrm{K}^{+}$channels controls fast inhibitory synaptic transmission at auditory outer hair cells. Neuron 26:595-601.

Pujol R, Lavigne-Rebillard M, Lenoir M (1998) Development of sensory and neural structures in the mammalian cochlea. In: Development of the auditory system (Rubel EW, Popper AN, Fay RR, eds), pp 146-192. New York: Springer.

Rajan R (2000) Centrifugal pathways protect hearing sensitivity at the cochlea in noisy environments that exacerbate the damage induced by loud sound. J Neurosci 20:6684-6693.

Robertson D (2009) Centrifugal control in mammalian hearing. Clin Exp Pharmacol Physiol 36:603-611.

Robertson D, Gummer M (1985) Physiological and morphological characterization of efferent neurones in the guinea pig cochlea. Hear Res 20:63-77.

Robinson BL, McAlpine D (2009) Gain control mechanisms in the auditory pathway. Curr Opin Neurobiol 19:402-407.

Rothlin CV, Katz E, Verbitsky M, Elgoyhen AB (1999) The alpha9 nicotinic acetylcholine receptor shares pharmacological properties with type A gamma-aminobutyric acid, glycine, and type 3 serotonin receptors. Mol Pharmacol 55:248-254.

Rothlin CV, Lioudyno MI, Silbering AF, Plazas PV, Casati ME, Katz E, Guth PS, Elgoyhen AB (2003) Direct interaction of serotonin type 3 receptor ligands with recombinant and native alpha 9 alpha 10-containing nicotinic cholinergic receptors. Mol Pharmacol 63:1067-1074.

Rüttiger L, Sausbier M, Zimmermann U, Winter H, Braig C, Engel J, Knirsch M, Arntz C, Langer P, Hirt B, Müller M, Köpschall I, Pfister M, Münkner S, Rohbock K, Pfaff I, Rüsch A, Ruth P, Knipper M (2004) Deletion of the $\mathrm{Ca}^{2+}$-activated potassium (BK) alpha-subunit but not the BKbeta1subunit leads to progressive hearing loss. Proc Natl Acad Sci U S A 101:12922-12927.

Schikorski T, Stevens CF (1997) Quantitative ultrastructural analysis of hippocampal excitatory synapses. J Neurosci 17:5858-5867.
Sgard F, Charpantier E, Bertrand S, Walker N, Caput D, Graham D, Bertrand D, Besnard F (2002) A novel human nicotinic receptor subunit, alpha10, that confers functionality to the alpha9-subunit. Mol Pharmacol 61:150-159.

Simmons DD (2002) Development of the inner ear efferent system across vertebrate species. J Neurobiol 53:228-250.

Simmons DD, Mansdorf NB, Kim JH (1996) Olivocochlear innervation of inner and outer hair cells during postnatal maturation: evidence for a waiting period. J Comp Neurol 370:551-562.

Singer JH, Glowatzki E, Moser T, Strowbridge BW, Bhandawat V, Sampath AP (2009) Functional properties of synaptic transmission in primary sense organs. J Neurosci 29:12802-12806.

Tan MN, Robertson D, Hammond GR (2008) Separate contributions of enhanced and suppressed sensitivity to the auditory attentional filter. Hear Res 241:18-25.

Taranda J, Maison SF, Ballestero JA, Katz E, Savino J, Vetter DE, Boulter J, Liberman MC, Fuchs PA, Elgoyhen AB (2009) A point mutation in the hair cell nicotinic cholinergic receptor prolongs cochlear inhibition and enhances noise protection. PLoS Biol 7:e18.

Vetter DE, Katz E, Maison SF, Taranda J, Turcan S, Ballestero J, Liberman MC, Elgoyhen AB, Boulter J (2007) The alpha10 nicotinic acetylcholine receptor subunit is required for normal synaptic function and integrity of the olivocochlear system. Proc Natl Acad Sci U S A 104:20594-20599.

Warr WB, Boche JE (2003) Diversity of axonal ramifications belonging to single lateral and medial olivocochlear neurons. Exp Brain Res 153: 499-513.

Weisstaub N, Vetter DE, Elgoyhen AB, Katz E (2002) The alpha9alpha10 nicotinic acetylcholine receptor is permeable to and is modulated by divalent cations. Hear Res 167:122-135.

Wersinger E, McLean WJ, Fuchs PA, Pyott SJ (2010) BK channels mediate cholinergic inhibition of high frequency cochlear hair cells. PLoS One 5:e13836.

Wiederhold ML, Kiang NY (1970) Effects of electric stimulation of the crossed olivocochlear bundle on single auditory-nerve fibers in the cat. J Acoust Soc Am 48:950-965.

Wilson JL, Henson MM, Henson OW Jr (1991) Course and distribution of efferent fibers in the cochlea of the mouse. Hear Res 55:98-108.

Winslow RL, Sachs MB (1988) Single-tone intensity discrimination based on auditory-nerve rate responses in backgrounds of quiet, noise, and with stimulation of the crossed olivocochlear bundle. Hear Res 35:165-189.

Xu-Friedman MA, Regehr WG (2004) Structural contributions to shortterm synaptic plasticity. Physiol Rev 84:69-85.

Yoshida N, Shigemoto T, Sugai T, Ohmori H (1994) The role of inositol trisphosphate on ACh-induced outward currents in bullfrog saccular hair cells. Brain Res 644:90-100.

Zorrilla de San Martín J, Pyott S, Ballestero J, Katz E (2010) $\mathrm{Ca}^{2+}$ and $\mathrm{Ca}^{2+}$ activated $\mathrm{K}^{+}$channels that support and modulate transmitter release at the olivocochlear efferent-inner hair cell synapse. J Neurosci 30: 12157-12167.

Zucker RS, Regehr WG (2002) Short-term synaptic plasticity. Annu Rev Physiol 64:355-405. 